\title{
القدرة التنبؤية للبناء الأسري باستراتيجيات التعامل مع الضفوط النفسية لدى طلبة الجامعة
}

\author{
أحمد صمادي * و ميادة القرعان
}

The Predictability of Family Structure for Coping Strategies with Psychological Stress among College Students

Ahmad Smadi, Yarmouk Universirty, Jordan.

Mayadah Alquraan, Ministry of Education, Jordan.

Abstract: This study aimed at identifing the predictability of family structure for psychological stress coping strategies among college students. A volunteer convenient sample of (726) undergraduate college students at a Jordanian University, answered the Coping Strategies Scale which was used to achieve the aim of the study after considering its pychometric properties. The results indicated that the strategy of solving problems and interactive coping strategy were ranked first, whereas the relaxing and entertainment strategy was the last. Furthermore, the results indicated that multiple regression analysis suggests differences in the coping strategies among students based on the variables of (birthorder in favor of the last child in self blaming strategy, family monthly income in favor of less than 500 JD or less and fathers with master degrees or higher in the leisure and relaxation strategy, and level of father education in favor of high Diploma or less in feelings and religion strategies).

(Keywords: Family Structure, Coping Strategies, College Students).

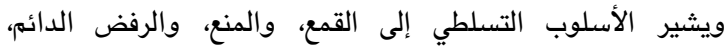

والمستمر لجميع مطالب الفرد، والقسوة والصرامة في التفاعل مع الأبناء،

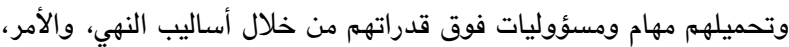
والعقاب، والحرمان، وهذا النوع من أساليب التعامل مع الأبناء يعني الإكثار

من تعظيم الأخطاء الصغيرة، والنقد اللاذع (Alkhazrajy, 2007) .

في حين يتمثل الأسلوب المتساهل في ترك الفرد لتحقيق رغباته

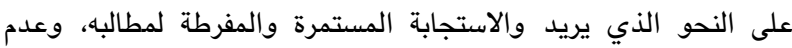

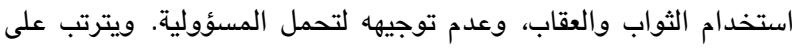

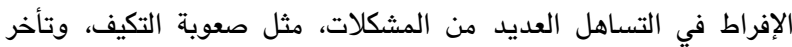
النضج، والثعور بالإحباط، والغضب (Alrashdan, 2005).
ملخص: هدفت الدراسة الحالية إلى الكثف عن القدرة التنبؤية للبناء الأسري

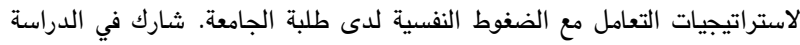

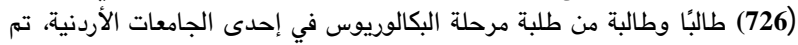

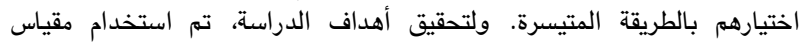

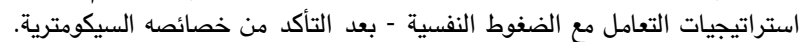

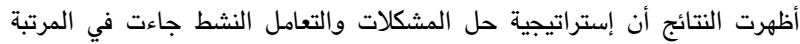

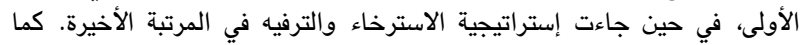

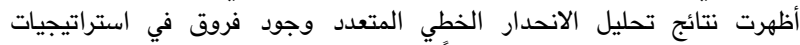

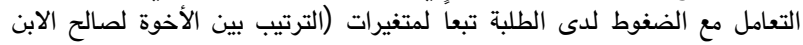

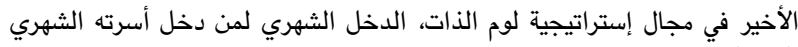

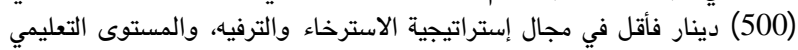

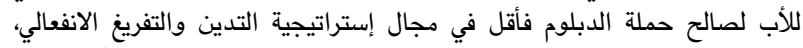

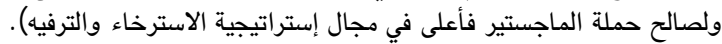

(الكلمات المفتاحية: البناء الأسري، استراتيجيات التعامل مع الضفوط النفسية،

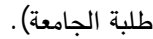

مقدمة: تعد الأسرة اللبنة الأساسية لتكوين المجتمع، والتي تسههم

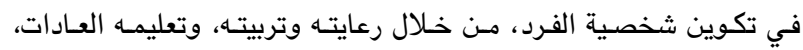

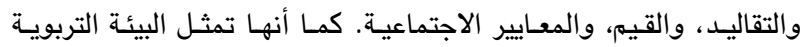

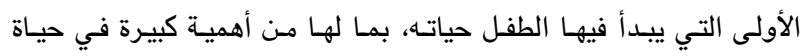

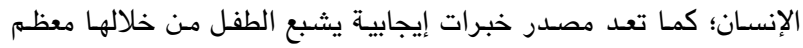

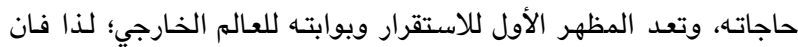

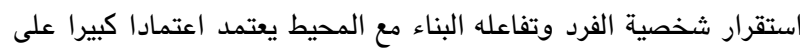
ما يسود الأسرة من علاقات اجتماعية تفاعلية.

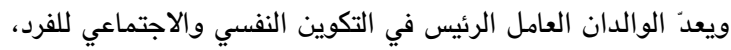

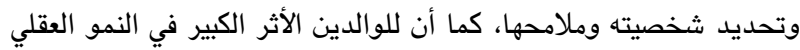

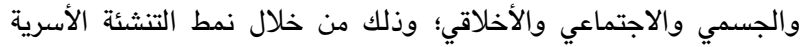

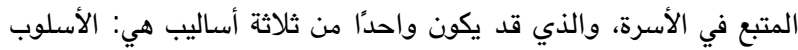

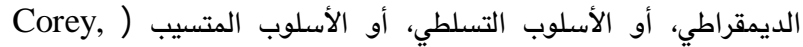

ففي الأسلوب الديمقراطي تقوم العلاقة بين الوالدين والأبناء على الدي

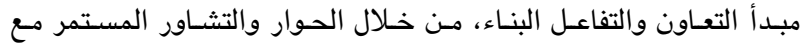

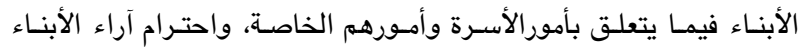

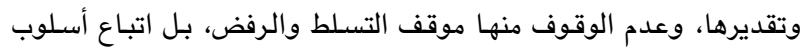
الإقناع واحترام الرأي والرأي الآخر (Aljbory, 1991) .

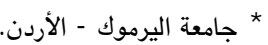
* * وزارة التربية والتعليم - الأردن. ( حقوق الطبع محفوظة لجامعة اليرموك، اربد، الأردن. 
كما أكد أدلر دور البناء الأسري في تشكيل شخصية الفرد،

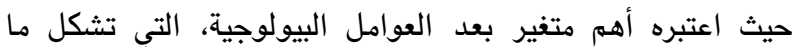

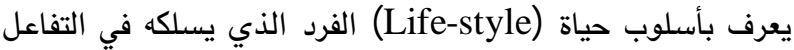

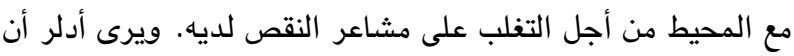

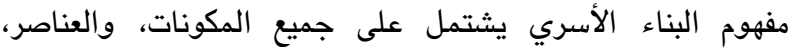

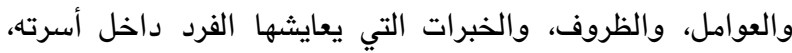
يضاف إلى ذلك الترتيب الولادي للطفل، ونمط تنشئة الأسرة التي

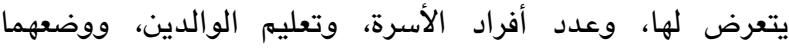

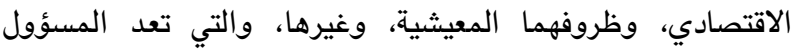
الأول عن تشكل أسلوب حياة الأفراد في تحقيق أهدافئه وافهم الحياتية،

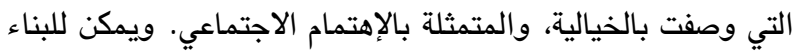

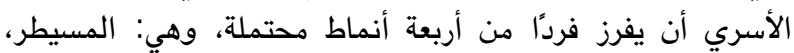

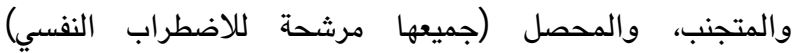

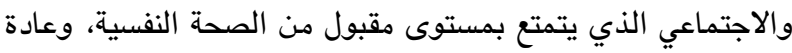

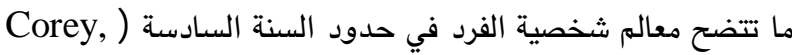
(2011

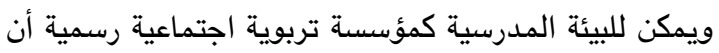

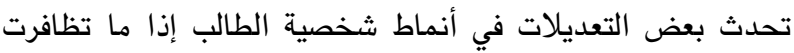

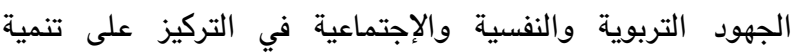
الإهتمام الإجتماعي لدى الطالب، من خلال الأنثطة الإنماعن المنهجية

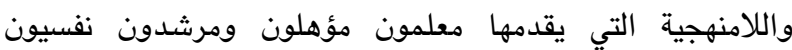
وتربويون وأخصائيون اجتماعيون. وعند انتقال الطلبة من البيئة

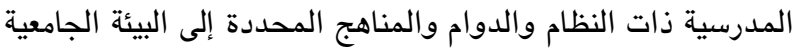

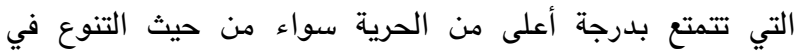

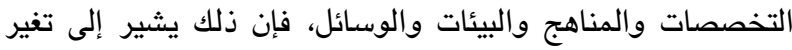

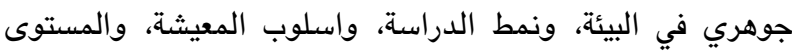

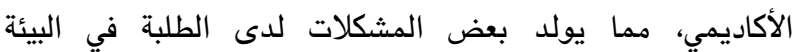

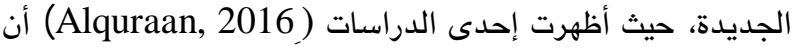

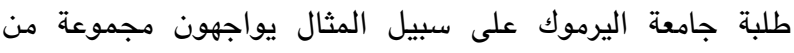
مصادر الضغوط، التي تتلخص في الضغوط الدراسية، والجامعية،

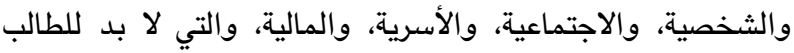

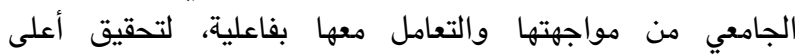
مستويات التوافق والنجاح في دراستهم الأكاديمية.

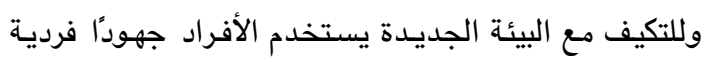

معرفية وسلوكية للتخفيف من أثار الأحداث الضـاغطة وتأثيراتها

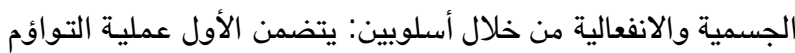

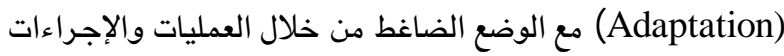

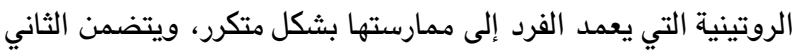

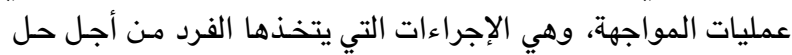

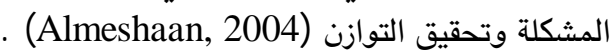

وتقوم الأسرة تجاه أبنائها بجملة من الوظائف، ولعل من أبرزها ما أوردته مزاهره (Mazahreh, 2009) • الوظيفة البيولوجية: والتي تقتصر على الإنجاب وتنظيمه. • الوظيفة الأمنية: فالأسرة في معظم المجتمعات تقدم لأبنائها

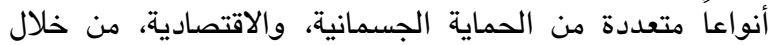
توفير المأوى، والغذاء، والدواء، والكساء.

• الوظيفة الاجتماعية: يقع على عاتق الأسرة تعليم الأبناء ثقافة

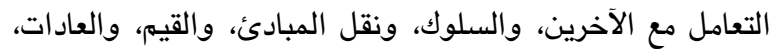

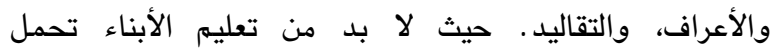

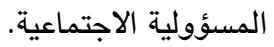

• الوظيفة النفسية: وتعد من أهم وظائف الأسرة، فهي التي تبث بين

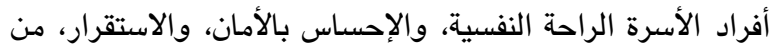

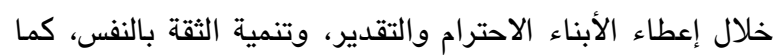
تساعدهم في حل مشاكلهم من خلال اكسابهم مهارات التكائه والتعامل مع مصادر الضغوط النفسية والاجتماعية.

• الوظيفة التربوية: تعمل الأسرة تربويا في تعليم الأبناء كيفية

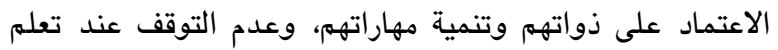

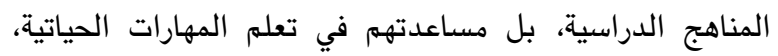

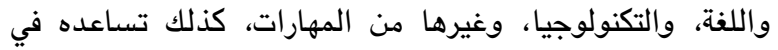

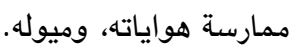

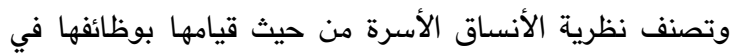

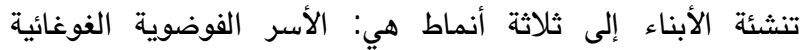

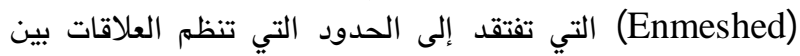

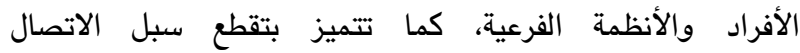

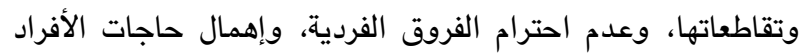

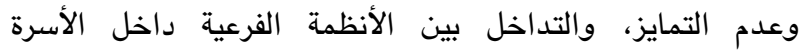
وخارجها، وتتصف كذلك بعدم استقرار القواعد والأنظمة، وأسالييها

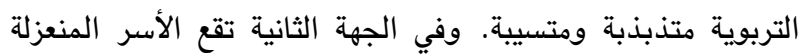

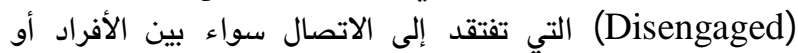
الأنظمة الفرعية داخل الأسرة الواحدة، كما تتميز بجمود التواء القوانين

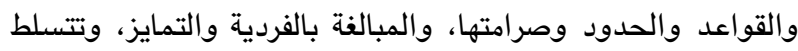

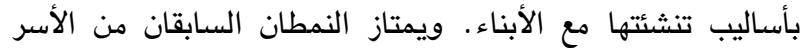

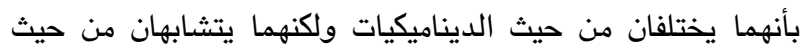
افرازاتهما لأشخاص مرشحين للإصابة ببعض الاضطرابات النفسية

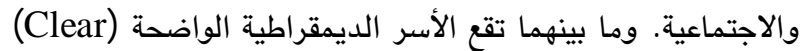

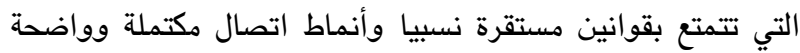
وأسلوبها في التنشئة يتسم بالديمقراطية، وتراعي الفروق الفردية الفئية

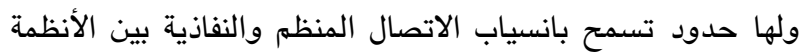

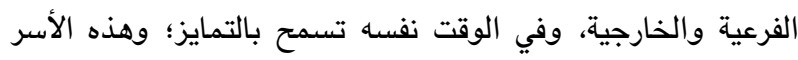
تفرز أشخاصًا أسوياء (Smadi \& Abdallah, 1996). 


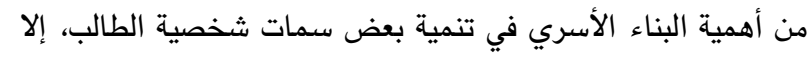

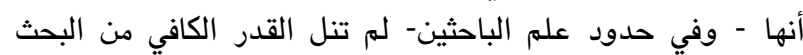

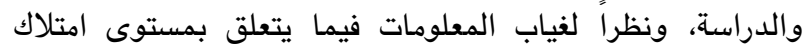

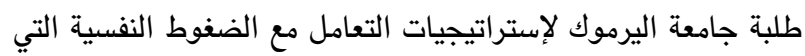

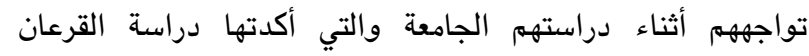

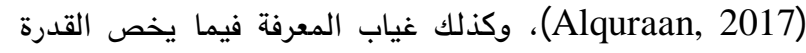

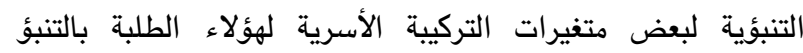

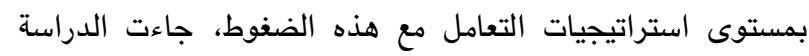

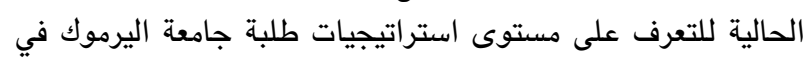

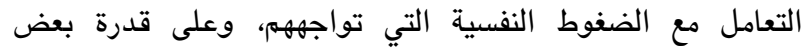

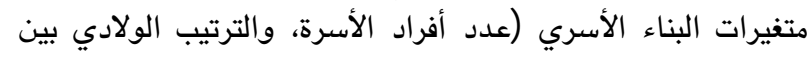

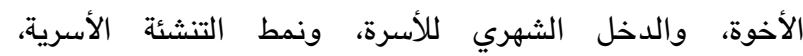

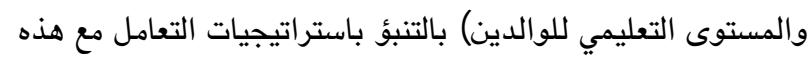

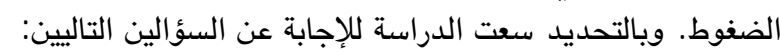

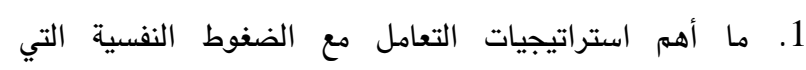
يستخدمها طلبة جامعة اليرموك؟

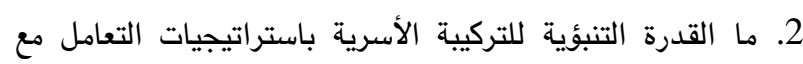

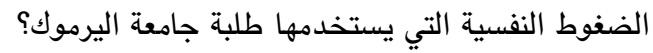

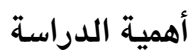

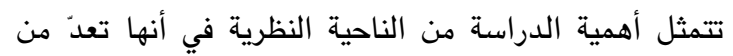

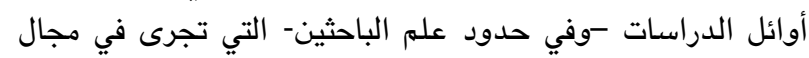

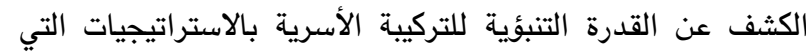

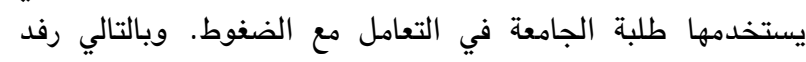

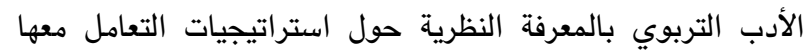

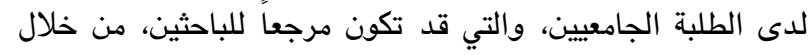

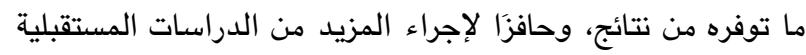

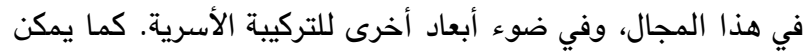

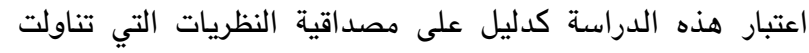

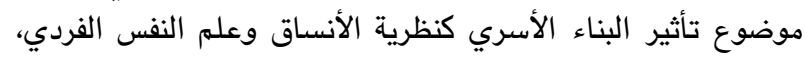
واستراتيجيات طلبة الجامعات في التعامل مع الضغوط.

ومن الناحية التطبيقية، يُؤمل من الدراسة الحالية توظيف

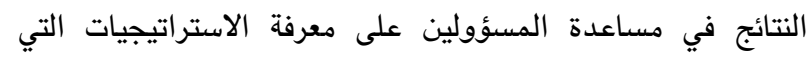

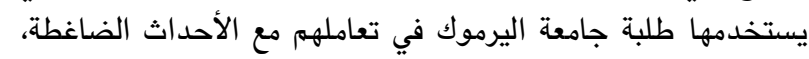

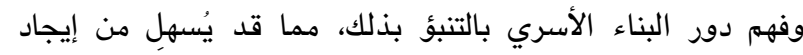

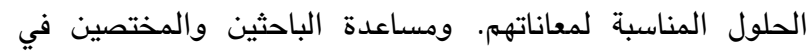

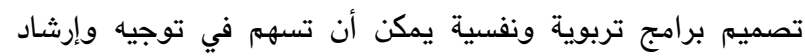

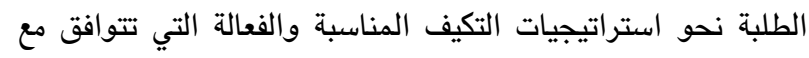

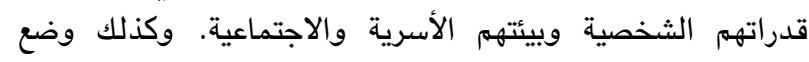

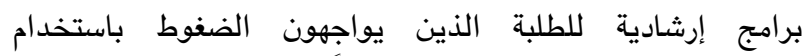

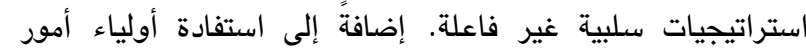

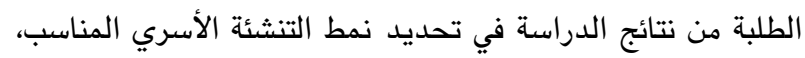
وأساليب التعامل مع أبنائهم، لاسيما في مرحلة الدراسة الجامعية.

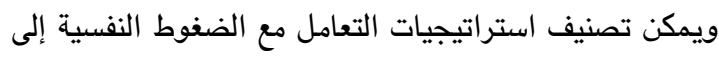

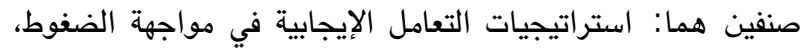

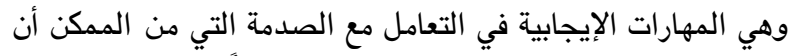

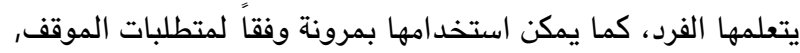

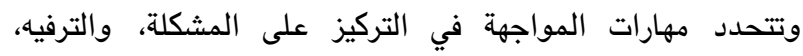

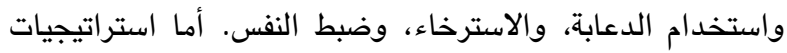

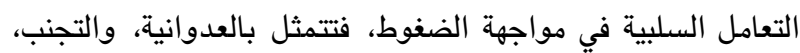

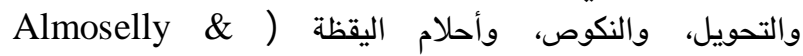

.)(Mahmoud, 2007

وحظي تأثير البناء الأسري في تكوين شخصية الفرد بأبعادها

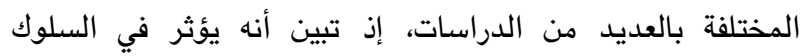

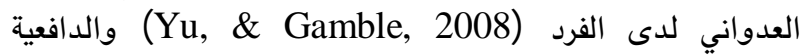
للتحصيل (Guasmeh \& Gharaibeh, 2005) العدواني لرى (201azam, 2010)، ومفهوم الذات لدى طلبة الجامعات ( \&ahafzah \& .(Alzuabi, 2008

أما فيما يخص تأثير البناء الأسري الذي يعيش فيه الفرد في

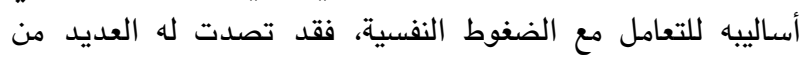

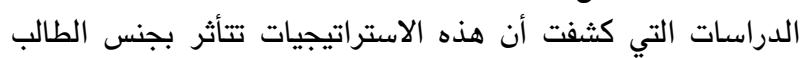

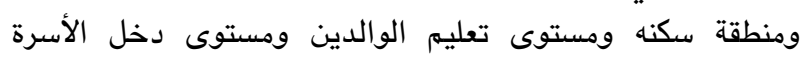
الشهري (Alahmad \& mariam, 2009,) :Alzuod, 2013, Alshakah, 2009 :Alzuabi, 2009, Kumar, \& Bhukar, ؛labad, 2013 ؛Budair, 2013, . (2013

ويلاحظ ندرة الدراسات السابقة التي تركز على معرفة

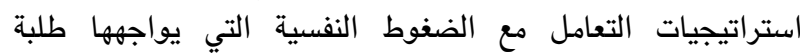

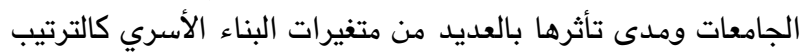

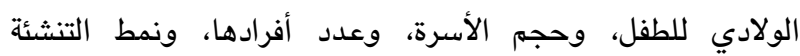

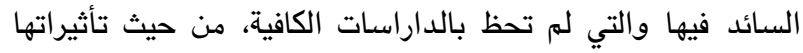

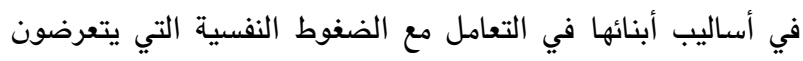

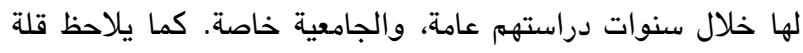

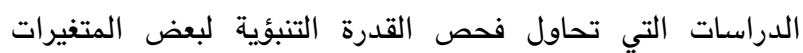

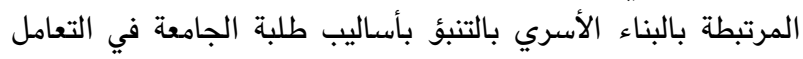

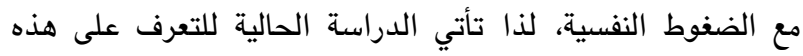

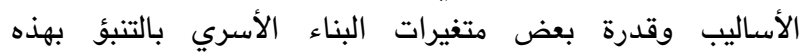

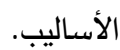

مشكلة الدراسة وسؤالها

أكدت العديد من الدراسات أهمية البناء الأسري في تحديد

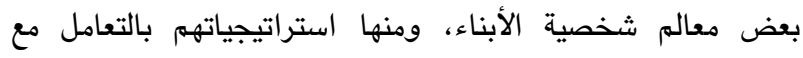

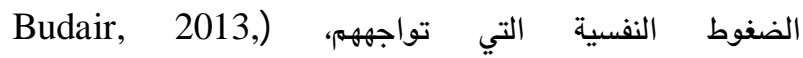
1shamari, 2015 ; 2013;Dukhan \& Alalhajar, 2006 O'Brien, ) و 2011; Labad, 2013 Sabbar, 2011,; (Mathieson, Leafman \& Spearman, 2012 


\begin{tabular}{|c|c|c|c|}
\hline المئوية & التكرار & مستويات & المتفير \\
\hline$\% 6.61$ & 48 & المتسلط & نمط التشثئة السيائد \\
\hline$\% 33.47$ & 243 & المتساهل & (من وحهة نظر \\
\hline$\% 59.92$ & 435 & الديمقراطي & (الطالب) \\
\hline$\% 100.00$ & 726 & الكلي & \\
\hline$\% 59.92$ & 435 & دبلوم فأقتل & \\
\hline$\% 30.85$ & 224 & بكالوريوس & المستوى \\
\hline$\% 9.23$ & 67 & ماجستير فأعلى & التعليمي \\
\hline$\% 100.00$ & 726 & الكلي & \\
\hline$\% 67.36$ & 489 & دبلوم فأقل & \\
\hline$\% 29.20$ & 212 & بكالوريوس & التمستوى \\
\hline$\% 3.44$ & 25 & ماجستير فأعلى & الأليمي \\
\hline$\% 100.00$ & 726 & الكلي & \\
\hline
\end{tabular}

يلاحظ من الجدول (1) قلة عدد المشاركين في الدراسة

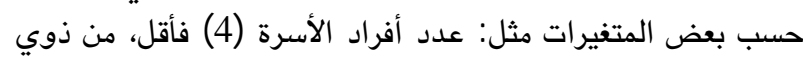
الدخل (1001) فأكثر، ممن يحمل الأب أو الأم ماجستير فأعلى.

مقياس استراتيجيات التعامل مع الضفوط النفسية

تم استخدام مقياس استراتيجيات التعامل مع الضفوط النفسية

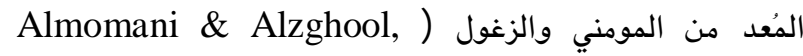

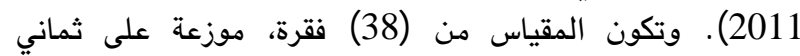

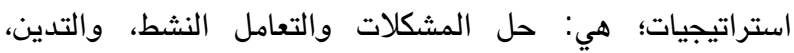

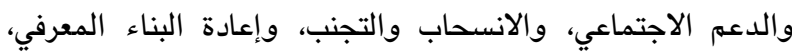
والتفريغ الانفعالي، ولوم الذات، والاسترخاء والترفيه. دلالات صدق المقياس الأصلي وثباته للتحقق من صدق المقياس، قام المومني والزغول (Almomani \& Alzghool, 2011) محكمين من أعضاء هيئة التدريس في قسمي الإرشاد وعلم النفس

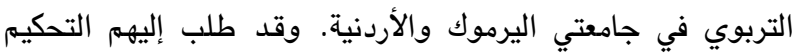

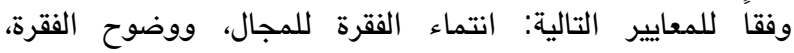

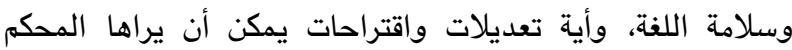

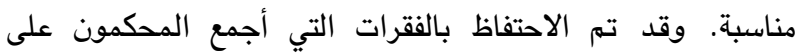

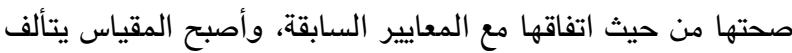

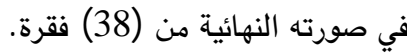

وللتأكد من صدق مقياس الاستراتيجيات الذي تم بناؤه من

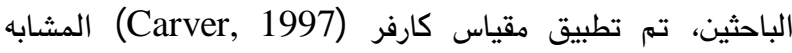

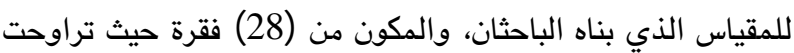

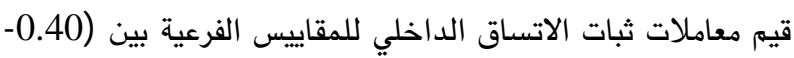
0.87)، كما تم تطبيق المقياس المعد من الباحثين على العين العينة

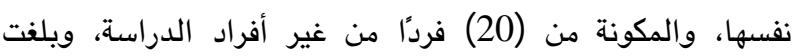
قيمة معامل الارتباط باستخدام معامل ارتباط بيرسون عن على الأبعاد الدراد

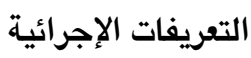

• استراتيجيات التعامل مع الضفوط: تعرف إجرائيًا بأنها الدرجة

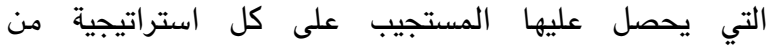
استراتيجيات التعامل التي تم استخدامها في هذه الدئ الدراسة. • البناء الأسري: يشير إلى العوامل والمتغيرات المتعلقة بالأسرة،

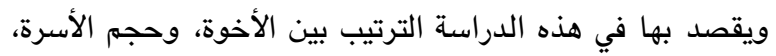

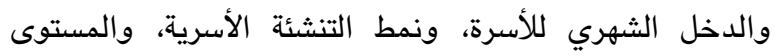

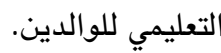
الطريقة

أفراد الدراسة

شارك في الدراسة الحالية (726) طالبًا وطالبة من طلبة جامعة اليرموك، تم اختيارهم بالطريقة المتيسرة من شعبتي العلوم

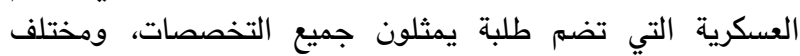
المستويات. حيث تم توزيع أدوات الدراسة على (757) طالبًا

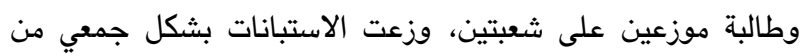

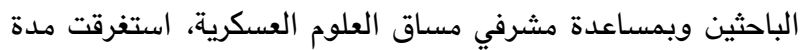

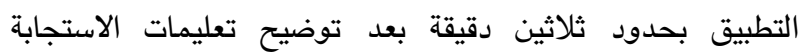

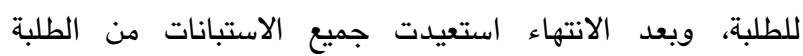

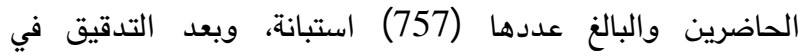
الاستبانات المرتجعة تم استبعاد (31) استبانة لعدم استكمال

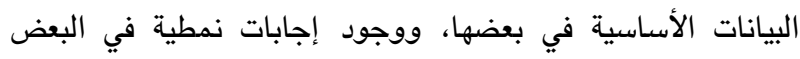

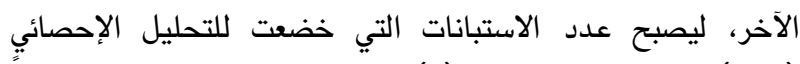
(726) استبانة. والجدول (1) يبين الآنياء توزيع عينة الدراسة وفقاً

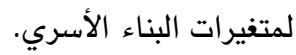
جدول (1): توزيع عينة الدراسة وفقًا لمتغيرات عناصر البناء

\begin{tabular}{|c|c|c|c|}
\hline \multirow{3}{*}{$\begin{array}{l}\text { النسبة } \\
\end{array}$} & \multirow{3}{*}{ التكرار } & \multicolumn{2}{|r|}{ الاسري } \\
\hline & & مستويات & المتفب \\
\hline & & المتفير & المضتير \\
\hline$\% 26.04$ & 189 & الأولَ & \multirow{4}{*}{ الترتيب بين الأخوة } \\
\hline$\% 57.16$ & 415 & الأوسط & \\
\hline$\% 16.80$ & 122 & الأخير & \\
\hline$\% 100.00$ & 726 & الكلي & \\
\hline$\% 7.72$ & 56 & 4 فأقل & \multirow{4}{*}{ عدد أفراد الأسرة } \\
\hline \%78.37 & 569 & $9-5$ & \\
\hline$\% 13.91$ & 101 & 10 فأكثر & \\
\hline$\% 100.00$ & 726 & الكلي & \\
\hline$\% 51.51$ & 374 & 500 فأقل & \multirow{4}{*}{ الدخل الشهري للأسرة } \\
\hline$\% 37.47$ & 272 & $501-1000$ & \\
\hline$\% 11.02$ & 80 & 1001 فأكثر & \\
\hline$\% 100.00$ & 726 & الكلي & \\
\hline
\end{tabular}


أعضاء هيئة التدريس في مجالات (علم النفس التربوي، والإرشاد

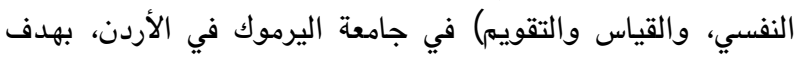

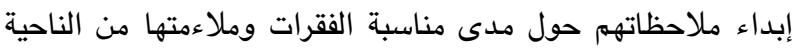

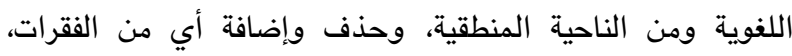

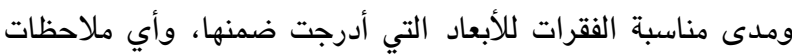
أو تعديلات يرونها مناسبة.

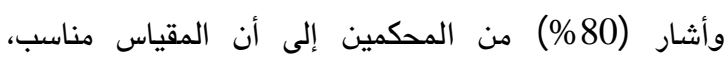

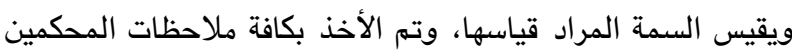

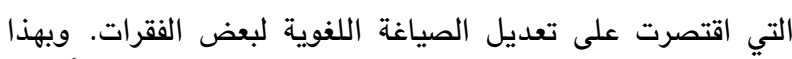

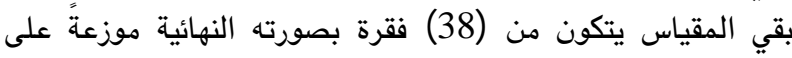

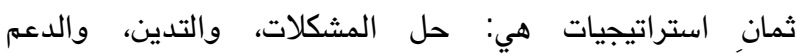

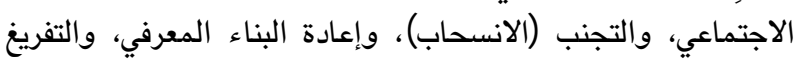
الانفعالي، ولوم الذات، والاسترخاء (الترفيه).

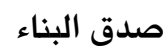

تم تطبيق أداة الدراسة على عينة استطلاعية مؤلفة من (50)

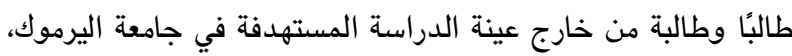

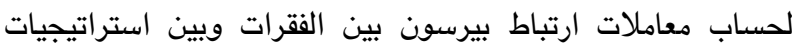
التعامل مع الضغوط النفسية التي تتتمي لها، والجدول (2) يبين زلك.
المتشابهة (حل المشكلات والتكيف النشط، والتدين، الدعم

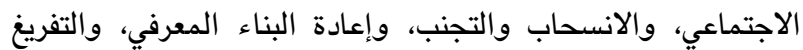

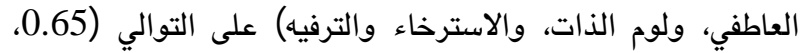

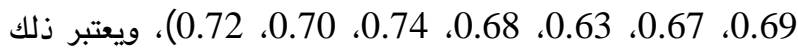
مؤشراً على تحقق ما يسمى بالصدق المرتبط بمحك وتحديداً

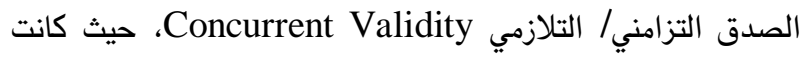
قيم معاملات الارتباط ذات دلالة التاني إحصائية عند مستوى الدلالة . $(\alpha=0.05)$

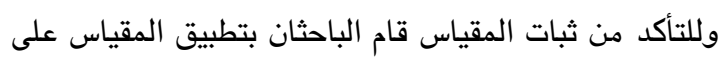

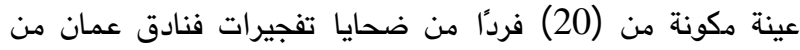

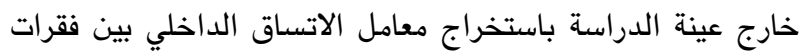
كل استراتيجية من مقياس الاستراتيجيات وبين فقرات المات المقياس الاست

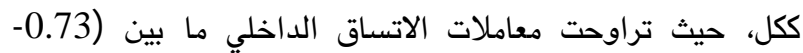

صدق المقياس الحالي وثباته

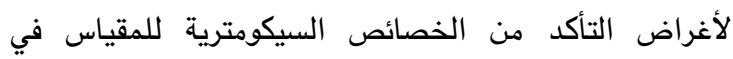
الدراسة الحالية استخدم الباحثان المؤشرات الآتية:

$$
\text { صدق المحتوى - n }
$$

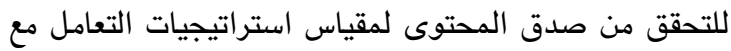

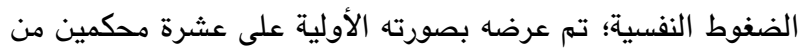

\begin{tabular}{|c|c|c|c|}
\hline الإرتباط مع & 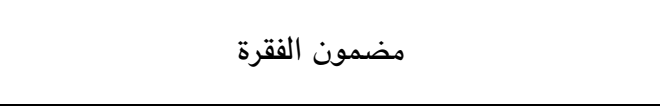 & رقتم & 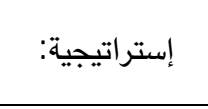 \\
\hline 0.51 & أعالج مشكلاتي منذ بداياتها وبدون تأجيل & 1 & \multirow{5}{*}{ حل حلتعامل النشلات } \\
\hline 0.55 & أتعايش مع الواقع & 9 & \\
\hline 0.58 & أنظر للمشكلة من جوانبها المختلفة & 17 & \\
\hline 0.49 & أقوم بجمع المعلومات عن المشكلة التي تواجهني & 25 & \\
\hline 0.53 & تكسبني الصعاب خبرات إيجابية & 32 & \\
\hline 0.53 & أصلي أكثر من المعتاد & 2 & \multirow{5}{*}{ 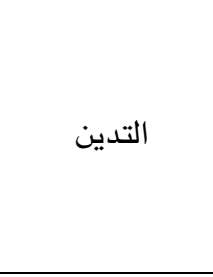 } \\
\hline 0.50 & أشاهد الفضائيات الدينية أكثر مما كنت عليه & 10 & \\
\hline 0.53 & أصل رحمي أكثر من السابق & 18 & \\
\hline 0.47 & أعتبر ما يحدث قضاءٌ وقدرًا & 26 & \\
\hline 0.52 & أقرأ القرآن الكريم أو أنصت إليه أكثر من السابق & 33 & \\
\hline 0.53 & أحصل على النصيحة من الآخرين & 3 & \multirow{5}{*}{ الدعم الاجتماعي } \\
\hline 0.54 & أتحدث إلى أصدقائي حول المشكلة التي تواجهني & 11 & \\
\hline 0.53 & أسأل الأشخاص الذين مروا بتجارب مشابهة عما فعلوه & 19 & \\
\hline 0.56 & أحصل على المساعدة من الآخرين & 27 & \\
\hline 0.52 & أبحث عن شخص يستمع لي & 34 & \\
\hline
\end{tabular}

جدول (2): معاملات الارتباط بين الفقرات وبين استراتيجيات التعامل مع الضغوط النفسية التي تنتمي لها 


\begin{tabular}{|c|c|c|c|}
\hline الإرتباط مع & 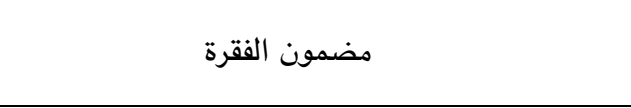 & رقمر & 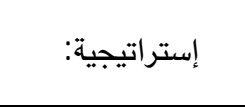 \\
\hline 0.47 & أنفرد بنفسي & 4 & \\
\hline 0.44 & 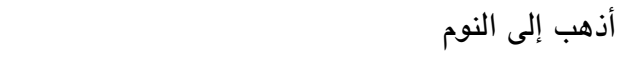 & 12 & \\
\hline 0.49 & ألجأ إلى تعاطي الأقراص المهدئة أكثر مما كنت عليه & 20 & الانسحاب والتجنب \\
\hline 0.52 & أتجنب مخالطة الناس & 28 & \\
\hline 0.47 & أتجنب القيام بأعمال تذكرني بالموقف المشكل & 35 & \\
\hline 0.54 & أقنع نفسي بأنني قادر على إيجاد حل للمشكلة & 5 & \\
\hline 0.55 & أنظر إلى المشكلة من منظور إيجابي & 13 & \\
\hline 0.58 & عندما أنظر إلى مشاكل الآخرين تهون عليّ مشكلتي & 21 & إعادة البناء المعرفي \\
\hline 0.46 & أغير من اتجاهاتي لأخفف من حدة المشكلة & 29 & \\
\hline 0.53 & أحدث نفسي بطريقة إيجابية & 36 & \\
\hline 0.46 & أتعامل مع الآخرين بعصيية & 6 & \\
\hline 0.52 & أنهمك بالعمل لأنسى همومي & 14 & \\
\hline 0.43 & أفكر بالأشياء السارة بدلًا من الانشغال بهمومي & 22 & التفريغ العاطفي \\
\hline 0.51 & أقوم بكبت مشاعري & 30 & \\
\hline 0.54 & ألجأ إلى البكاء & 37 & \\
\hline 0.65 & أشعر بالأسى لما يحدث معي & 7 & \\
\hline 0.71 & أعاقب نفسي نتيجة لما يحدث & 15 & 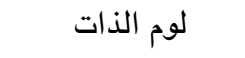 \\
\hline 0.63 & ألوم نفسي على ما يحدث & 23 & \\
\hline 0.53 & أذهب مع أصدقائي في نزهة & 8 & \\
\hline 0.48 & أمارس الرياضة & 16 & \\
\hline 0.48 & أمارس الاسترخاء بهدوء & 24 & الاسترخاء والترفيه \\
\hline 0.47 & أشاهد البرامج التلفزيونية & 31 & \\
\hline 0.49 & أستمع للموسيقى & 38 & \\
\hline
\end{tabular}

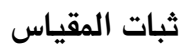

لأغراض التحقق من ثبات الاتساق الداخلي للأداة الحالية؛

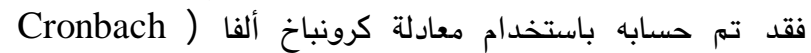
(Alpha

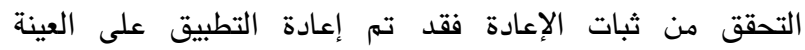

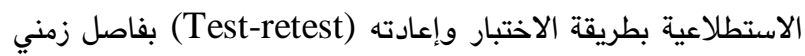

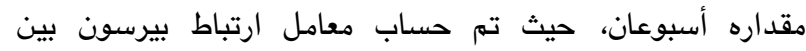
التطبيقين الأول والثاني على العينة الاستطلاعية، كما في الجدول بـان
يلاحظ من الجدول (2) أن قيم معاملات ارتباط الفقرات مع

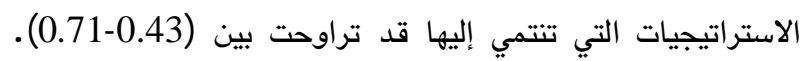

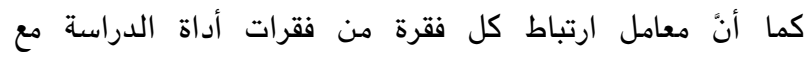

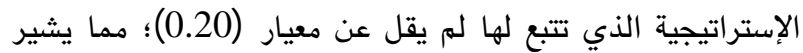

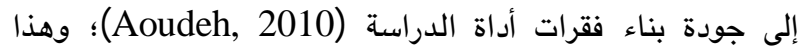
يؤكد مناسبة بناء فقرات أداة الدراسة. 


\begin{tabular}{|c|c|c|c|}
\hline عدد الفقرات & ثبات الإعادة & معامل الاتسـاق الداخلي & استراتيجيات التعامل مع الضفوط النفسية \\
\hline 5 & 0.81 & 0.67 & حل المشكلات والتعامل النشط \\
\hline 5 & 0.89 & 0.76 & 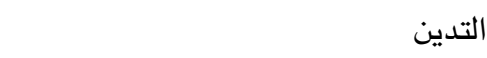 \\
\hline 5 & 0.75 & 0.69 & الدعم الاجتماعي \\
\hline 5 & 0.72 & 0.54 & الانسحاب والتجنب \\
\hline 5 & 0.88 & 0.59 & إعادة البناء المعرفي \\
\hline 5 & 0.89 & 0.70 & التفريغ الانفعالي \\
\hline 3 & 0.69 & 0.53 & 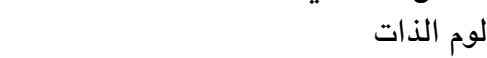 \\
\hline 5 & 0.82 & 0.50 & الاسترخاء والترفيه \\
\hline
\end{tabular}

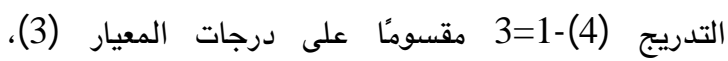

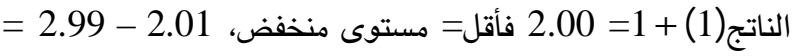
مستوى متوسط، 3.00 فأكثر= مستوى مرتفع.

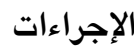

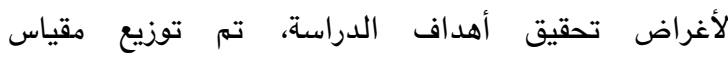

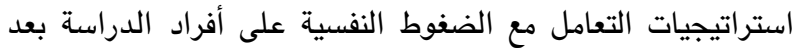

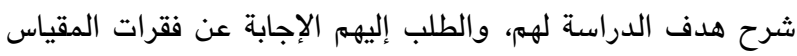

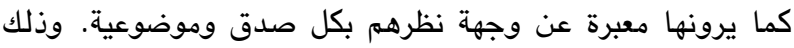

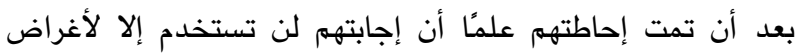

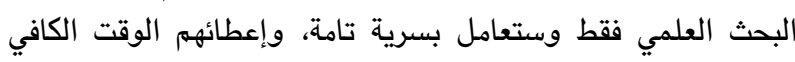

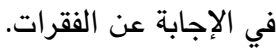

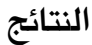
1- النتائج المتعلقة بالسؤال الأول: ما أهم استراتيجيات التعامل

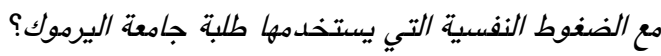
للإجابة عن هذا السؤال، تم حساب المتوسطات الحسابية

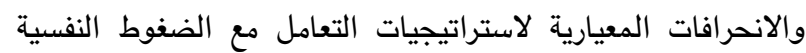

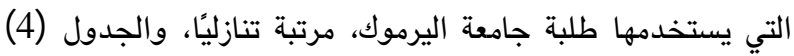
يوضح ذلك.

ويمكن تفسير تدني معاملات الاتساق الداخلي في ضوء

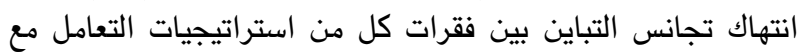

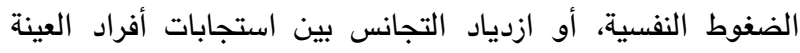

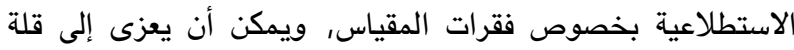
عدد الفقرات في بعض الأبعاد .

معيار تصحيح مقياس استراتيجيات التعامل مع الضفوط النفسية

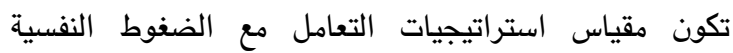
بصورته النهائية من (38) فقرة، وتمت الإجابة عن فقرات مقياس

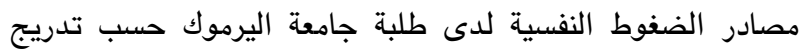

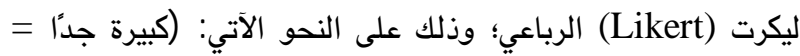

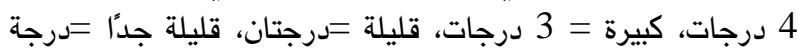

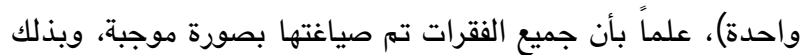
تكون أعلى علامة يحصل عليها المستجيب (152) وأدنى علامة

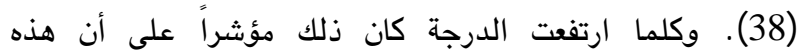

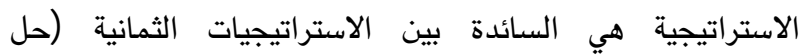

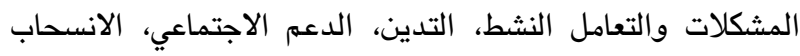

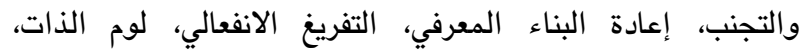

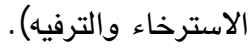

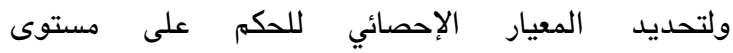
الاستراتيجيات تم تطبيق المعادلة الإحصائية التالية: جدول (4): المتوسطات الحسابية والانحرافات المعيارية لاستراتيجيات التعامل مع مصادر الضفوط النفائية النفية التي يستخدمها طلبة جامعة

\begin{tabular}{|c|c|c|c|c|}
\hline \multicolumn{5}{|c|}{ ليرموك، مرتبةً تنازليًا وفقًا لأوساطها الحسابية } \\
\hline 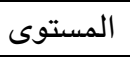 & الانحراف المعياري & الوسط الحسابي & استراتيجيات التعامل مع مصادر الضغوط النفسية & 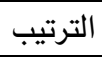 \\
\hline متوسط & 0.52 & 2.96 & حل المشكلات والتعامل النشط & 1 \\
\hline 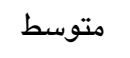 & 0.52 & 2.89 & إعادة البناء المعرفي & 2 \\
\hline 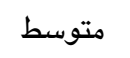 & 0.52 & 2.88 & الدعم الاجتماعي & 3 \\
\hline 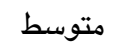 & 0.49 & 2.88 & 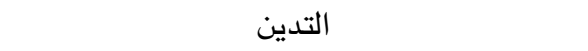 & 4 \\
\hline 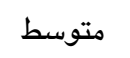 & 0.49 & 2.68 & الانسحاب والتجنب & 5 \\
\hline متوسط & 0.51 & 2.67 & 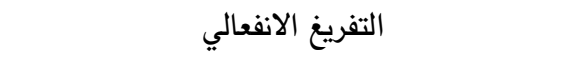 & 6 \\
\hline 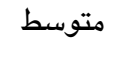 & 0.69 & 2.64 & 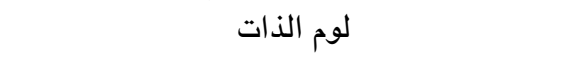 & 7 \\
\hline 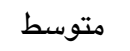 & 0.51 & 2.60 & الاسترخاء والترفيه & 8 \\
\hline
\end{tabular}


السادسة، واستراتيجية لوم الذات في المرتبة السابعة، وأخيرًا؛ استراتيجية الاسترخاء والترفيه في المرتبة الثامنة.

2- النتائج المتعلقة بالسؤال الثاني: ما القدرة التنبؤية للتركيية

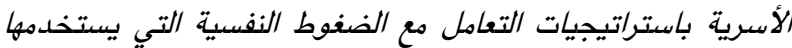
طلبة جامعة اليرموك؟ باستراتيات

للإجابة عن هذا السؤال تم استخدام تحليل الانحدار الخطي إلِي

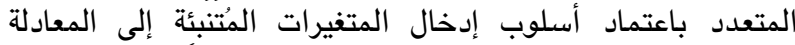

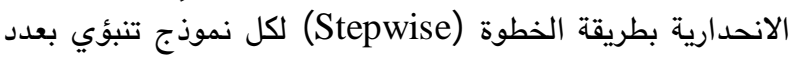
المتغيرات المتنبأ بها، والجدول (5) يوضح ذلك.
يلاحظ من الجدول (4) أنُ مستوى جميع استراتيجيات

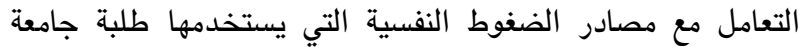

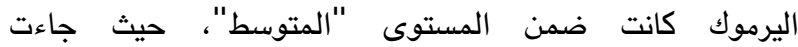
استراتيجيات التعامل مع مصادر الضفوط النفسية التي يستخدمها طلبة جامعة اليرموك وفقا لأهميتها لدى الطلبة على الترتيب الآتي:

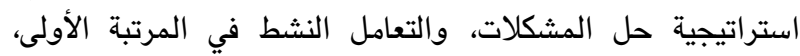

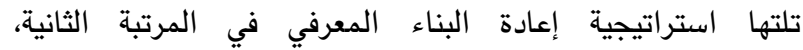
واستراتيجية الدعم الاجتماعي في المرتبة الثالثة، ثم استراتيجية

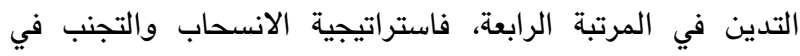
المرتبة الخامسة، ثم استراتيجية التفريغ الانفعالي في المرتبة التبه

جدول (5)): نتائج اختبار الفرضيات الانحدارية للمتغيرات المتنبئة من متغيرات البناء الأسري ومعاملات الارتباط المتعددة لها ومقدار تفسيرها حسب أسلوب إدخال المتغيرات المتنبئة Stepwise على المعادلة الانحدارية لكل نموذ ج تنبؤي

\begin{tabular}{|c|c|c|c|c|c|c|c|c|c|c|}
\hline \multicolumn{5}{|c|}{ إحصائيات التغير } & \multirow[b]{2}{*}{ اللتقدير } & \multirow[b]{2}{*}{ المعدل } & \multirow[b]{2}{*}{2} & \multirow[b]{2}{*}{ J } & \multirow[b]{2}{*}{ النموذج } & \multirow[b]{2}{*}{ إستراتيجية } \\
\hline الإحصائية الدلة & لدرجة & حرجة & التغير & للتغير & & & & & & \\
\hline 0.01 & 724 & 1 & 6.10 & $0.84 \%$ & 2.60 & $0.70 \%$ & $0.84 \%$ & 0.09 & 1 & 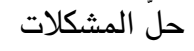 \\
\hline \multicolumn{9}{|c|}{ المتنبئات: (ثابت الانحدار)، المستوى التعليمي لأمي دبلوم فأقل } & أ & والتعامل النشط \\
\hline 0.01 & 724 & 1 & 6.58 & $0.90 \%$ & 2.43 & $0.76 \%$ & $0.90 \%$ & 0.09 & 1 & \multirow[b]{3}{*}{ التدين } \\
\hline 0.03 & 723 & 1 & 4.74 & $0.65 \%$ & 2.43 & $1.27 \%$ & $1.55 \%$ & 0.12 & -2 & \\
\hline \multicolumn{9}{|c|}{ 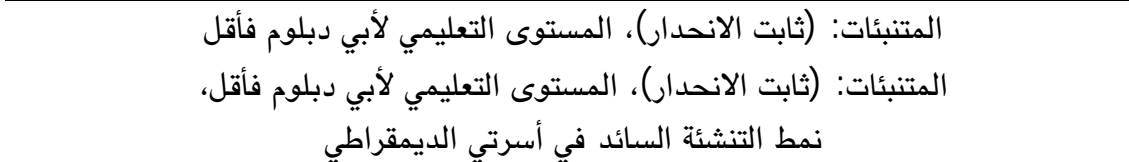 } & أ & \\
\hline 0.37 & 713 & 12 & 1.08 & $1.79 \%$ & 2.61 & $0.14 \%$ & $1.79 \%$ & 0.13 & 1 & \multirow{2}{*}{ الاجتماعي } \\
\hline \multicolumn{9}{|c|}{ المتنبئات: (ثابت الانحدار)، جميع المتنبئات وفقا لطريقة الإدخال } & أ & \\
\hline 0.02 & 724 & 1 & 5.68 & $0.78 \%$ & 2.43 & $0.64 \%$ & $0.78 \%$ & 0.09 & 1 & 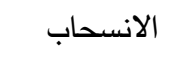 \\
\hline \multicolumn{9}{|c|}{ المتنبئات: (ثابت الانحدار)، المستوى التعليمي لأمي ماجستير } & i & والتجنب \\
\hline 0.00 & 724 & 1 & 11.79 & $1.60 \%$ & 2.57 & $1.47 \%$ & $1.60 \%$ & 0.13 & 1 & \multirow{4}{*}{ إعادة البناء } \\
\hline 0.03 & 723 & 1 & 4.52 & $0.61 \%$ & 2.56 & $1.94 \%$ & $2.21 \%$ & 0.15 & -2 & \\
\hline \multicolumn{9}{|c|}{ المتنبئات: (ثابت الانحدار)، المستوى التعليمي لأمي دبلوم فأقل } & i & \\
\hline \multicolumn{9}{|c|}{ المتنبئات: (ثابت الانحدار)، المستوى التعليمي لأمي دبلوم فأقل، ترتيبي الأوسط بين أخوتي } & ب & \\
\hline 0.00 & 724 & 1 & 8.91 & $1.22 \%$ & 2.51 & $1.08 \%$ & $1.22 \%$ & 0.11 & 1 & \multirow{2}{*}{ الانفعالي } \\
\hline \multicolumn{9}{|c|}{ المتنبئات: (ثابت الانحدار)، المستوى التعليمي لأبي دبلوم فأقل } & i & \\
\hline 0.00 & 724 & 1 & 8.36 & $1.14 \%$ & 2.06 & $1.00 \%$ & $1.14 \%$ & 0.11 & 1 & لوم \\
\hline \multicolumn{9}{|c|}{ المتنبئات: (ثابت الانحدار)، ترتيبي الأخير بين أخوتي } & i & الذات \\
\hline 0.01 & 724 & 1 & 6.09 & $0.83 \%$ & 2.57 & $0.70 \%$ & $0.83 \%$ & 0.09 & 1 & \multirow[b]{3}{*}{ والترفيه - (الاءترخاء } \\
\hline 0.02 & 723 & 1 & 5.39 & $0.73 \%$ & 2.56 & $1.30 \%$ & $1.57 \%$ & 0.13 & -2 & \\
\hline \multicolumn{9}{|c|}{ 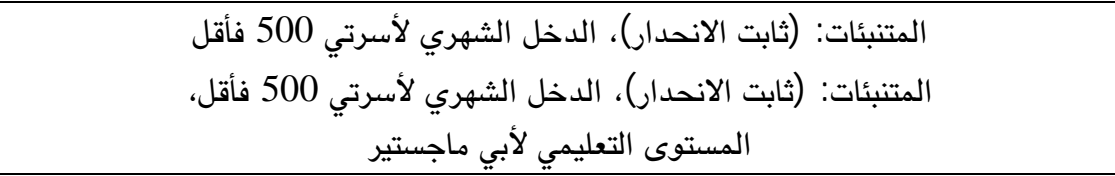 } & i & \\
\hline
\end{tabular}


(التابعة) وهي استراتيجيات التعامل مع الضغوط النفسية (حل

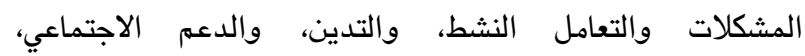

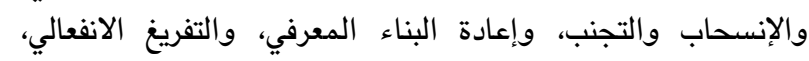

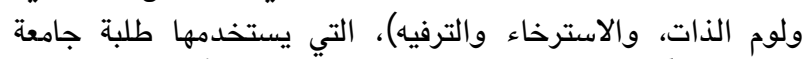

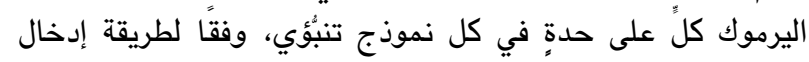

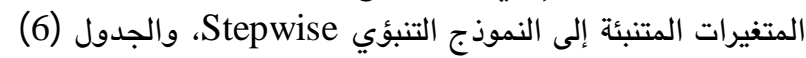
يوضح ذلك.
تم حساب أوزان الانحدار اللامعيارية، والمعيارية، وقيم (ت)

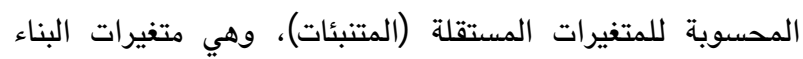

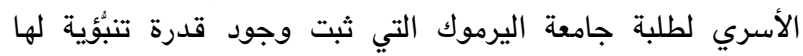

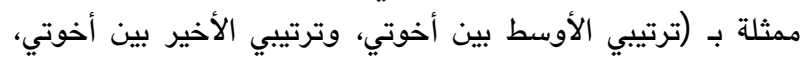

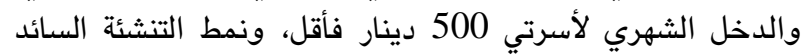

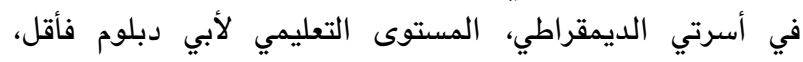

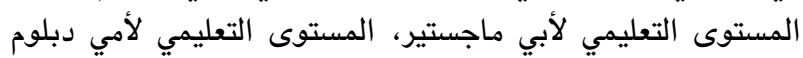

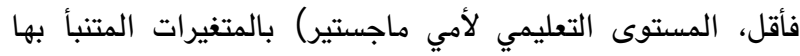

جدول (6): الأوزان اللامعيارية والمعيارية للمتغيرات المتنبئة من متفيرات البناء الأسري بالمتغيرات المتنبأ بها من استراتيجيات التعامل مع

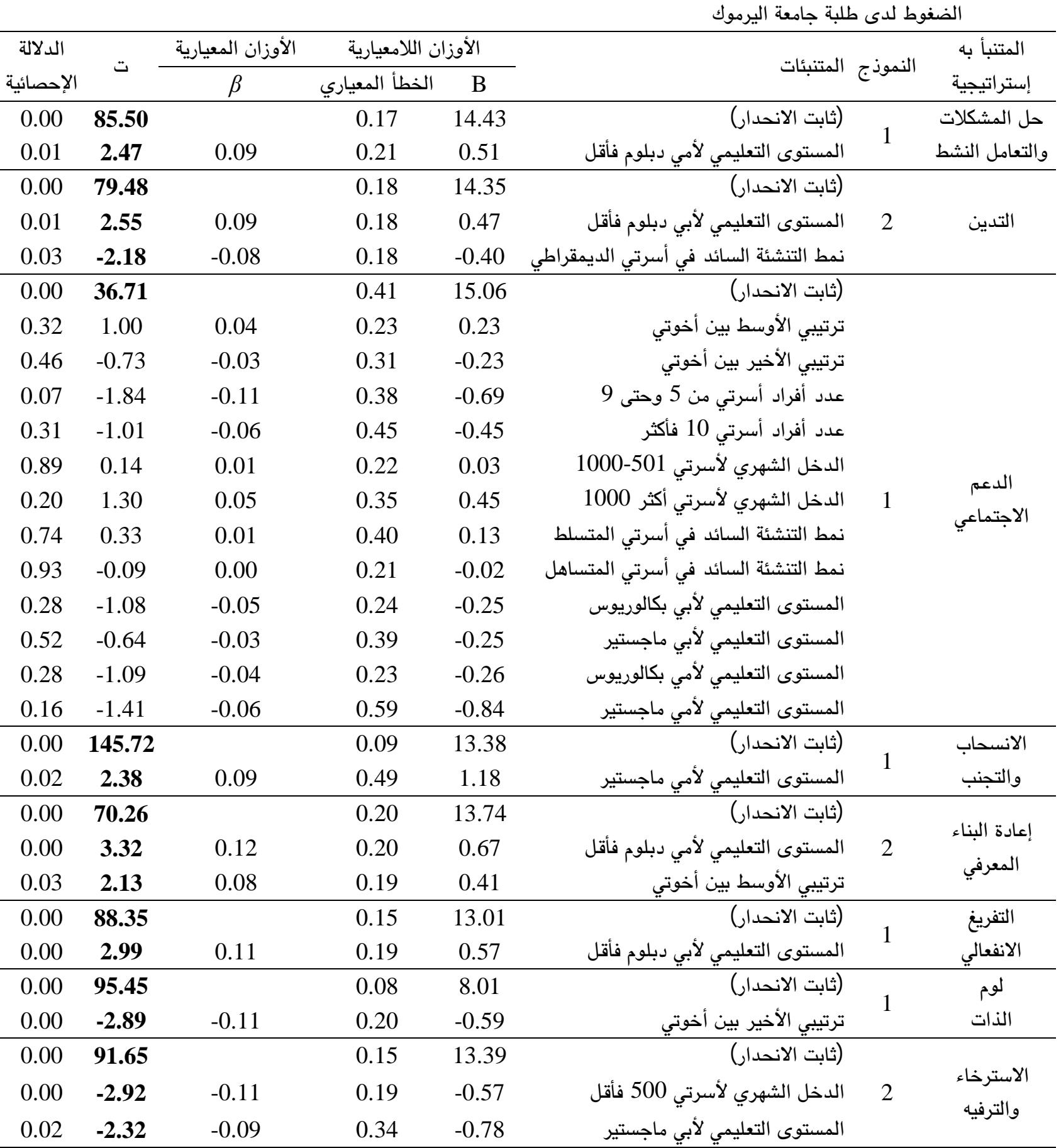


و . نتائج النموذج التنبؤي الفرعي الأوَّل وفقًا للنموذج التنبؤي الرئيس

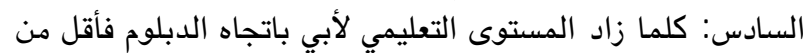

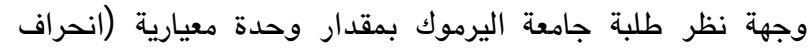

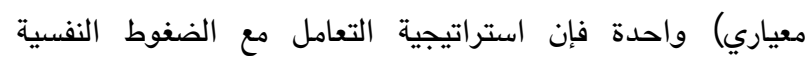

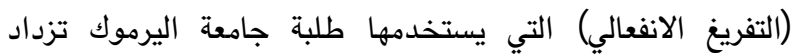

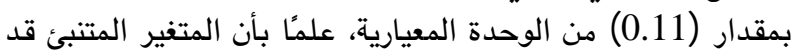

كان دالاً إحصائيًا.

ز. نتائج النموذج التنبؤي الفرعي الأوّل وفقًا للنموذج التتبؤي الرئيس

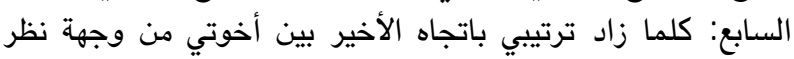

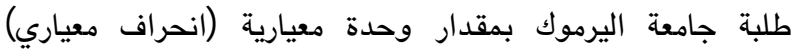

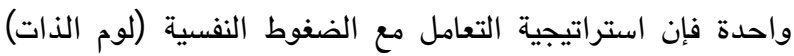

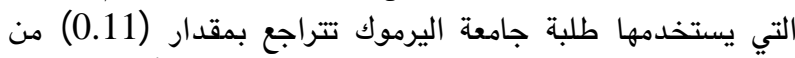
الوحدة المعيارية، علمًا بأن المتغير المتنبئ قد كان دالئه دالاً إحصائيًا.

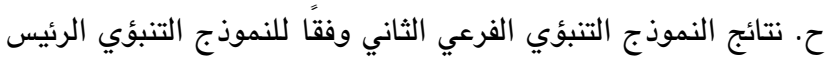

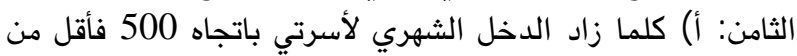

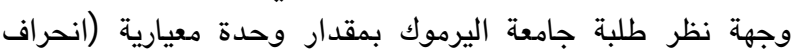

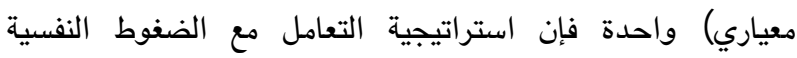

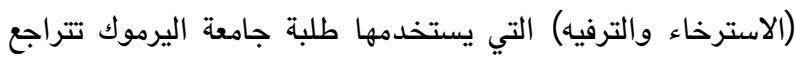

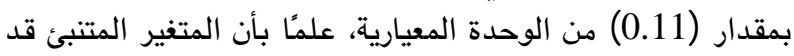

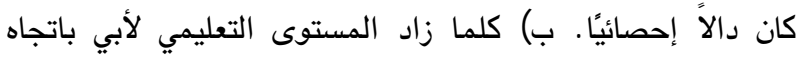

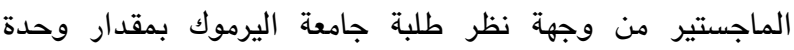

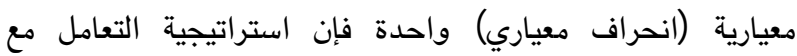

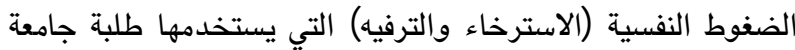

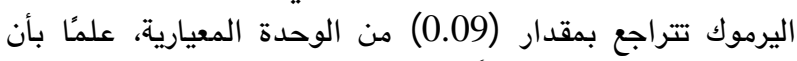
المتغير المتنبئ قد كان دالاً إحصائيًا.

المناقشة

أشارت نتائج الدراسة إلى تنوع الاستراتيجيات التي يستخدمها

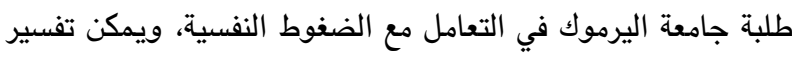

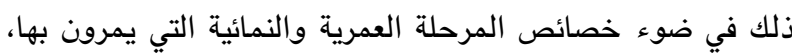

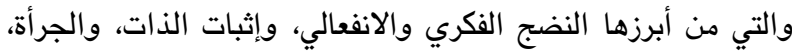

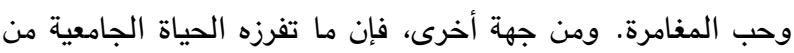

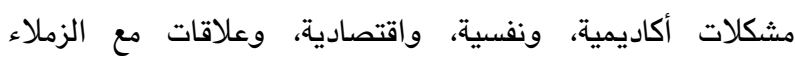

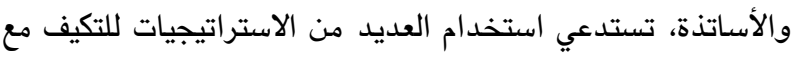

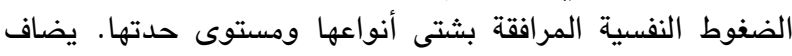

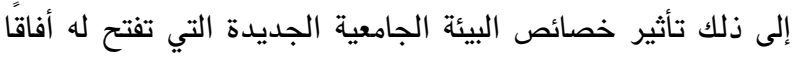

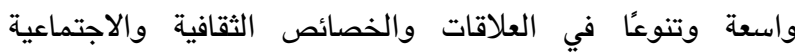

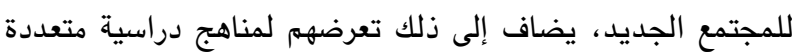

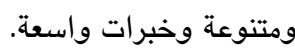

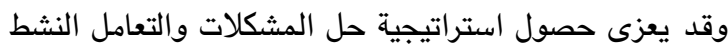

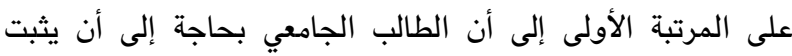

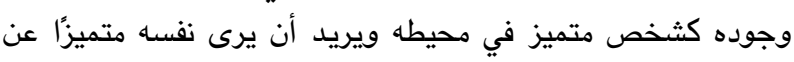
الآخرين، مما يدفعه إلى مواجهة الواقع، إضافة إلى الطبيعة
يتضح من الجدول (6) أن النتائج الخاصة بالنماذج التنبؤية

$$
\text { الرئيسة الستة كانت على النحو الآتي: }
$$

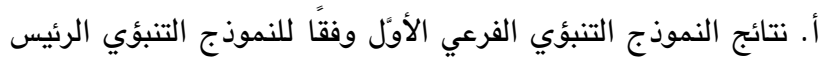

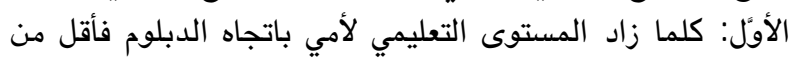

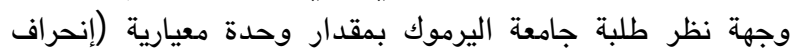

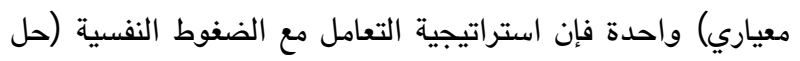

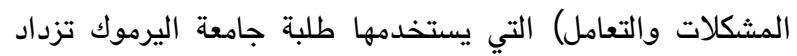

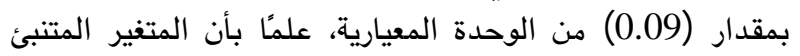
قد كان دالاً إحصائيًا.

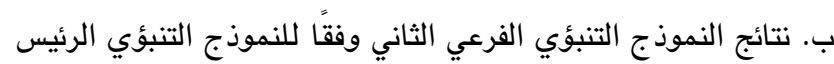

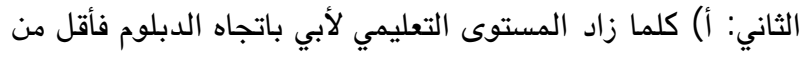

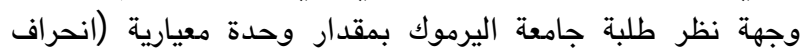

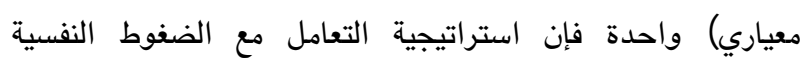
(التدين) التي يستخدمها طلبة جامعة اليرموك تزداد التماد بمقدار 0.09

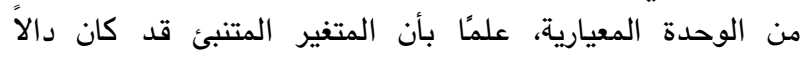

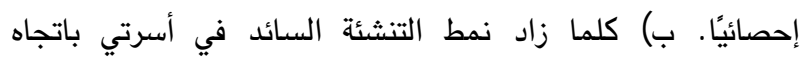

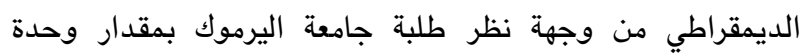

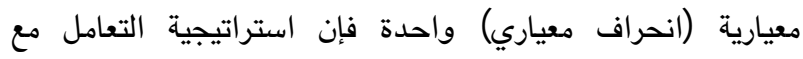

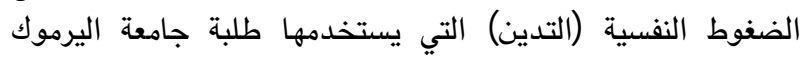

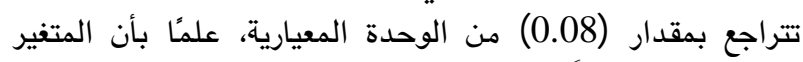
المتنبئ قد كان دالاً إحصائيًا.

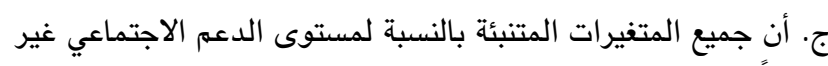

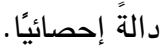

د. ـ نتائج النموذج التنبؤي الفرعي الأولّ وفقًا للنموذج التنبؤي الرئيس

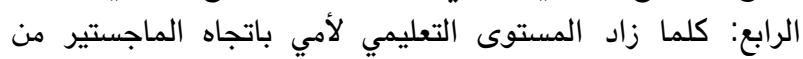

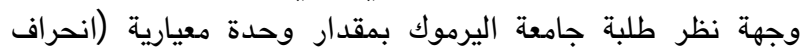

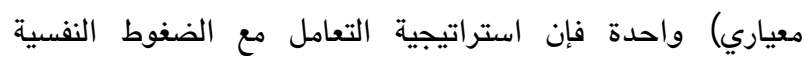

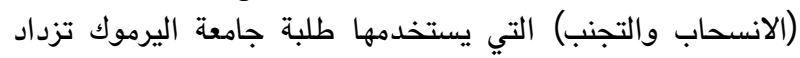

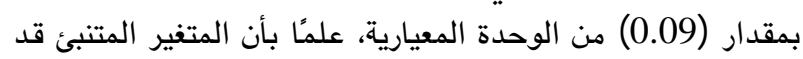

كان دالاً إحصائيًا.

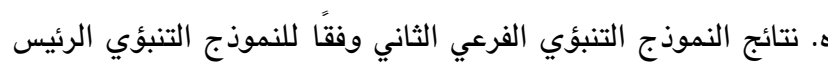

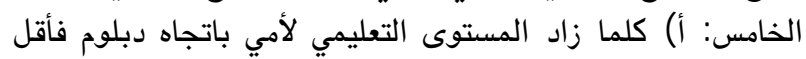

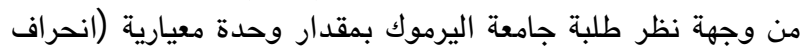

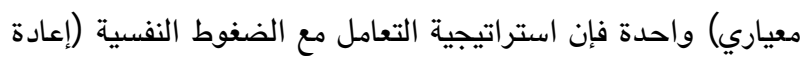

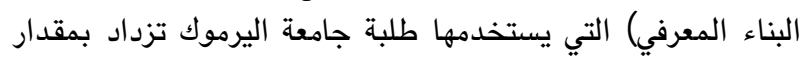

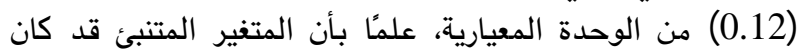

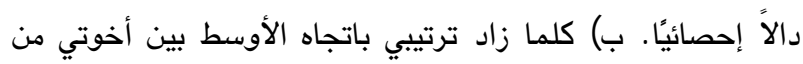

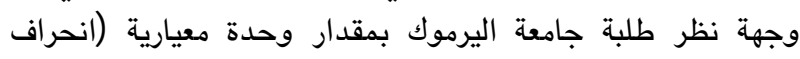

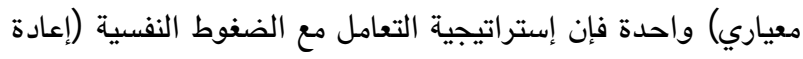

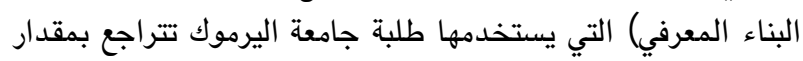

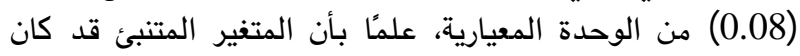
دالاً إحصائيًا. 
استراتيجيات لوم الذات والاسترخاء والترفيه للتفاعل مع الضغوط النفسية.

كما أشارت النتائج إلى أنه كلما كان المستوى التعليمي للأم

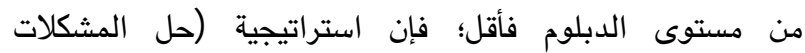

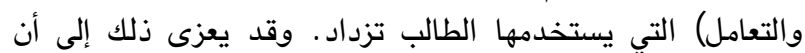
مستوى التعليمي دبلوم فأقل لدى الأم، ربما يدفعها إلى الاستعانة

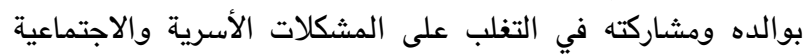
والاقتصادية التي تواجههم، مما يكسبه الخبرة في حل المشكلات.

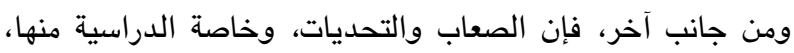
التي تواجه الطلبة، وليس لدى وانب والدته القدرة على مساعدته فيها،

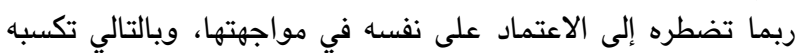

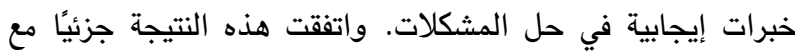

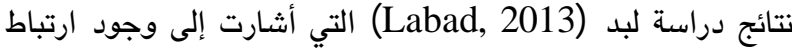

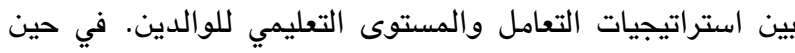

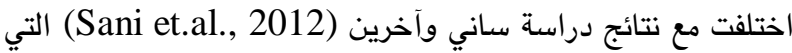
أشارت إلى أن عدد أفراد الأسرة لا يرتبط باسئ واستراتينيات التئ التفاعل مع

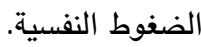

وكثفت النتائج كذلك أنه كلما زاد المستوى التعليمي للأب باتجاه الدبلوم فأقل؛ فإن استراتيجية (التدين) التي يستخدمها التها الطالب تزداد. وقد يعزى ذلك إلى تأثير الثقافة الدينية للمجتمع

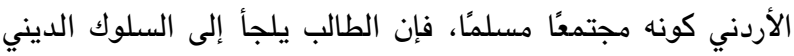

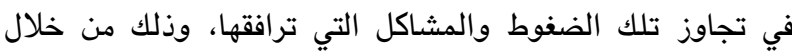

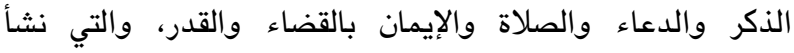

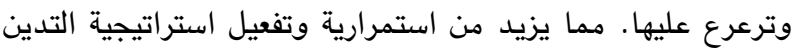

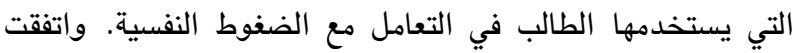
هذه النتيجة جزئيًا مع نتائج دراسة لبد البئ (Labad, 2013) التي

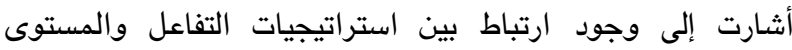

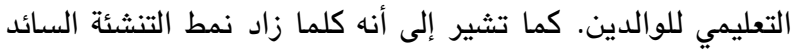

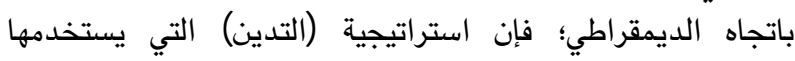
الطالب تتراجع. ويمكن تفسير ذلك في ضوء طبيعة التنشئة الوالدية

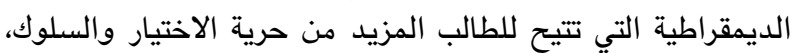

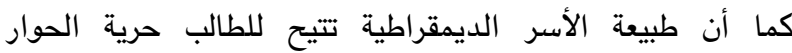

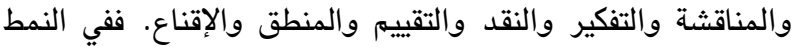

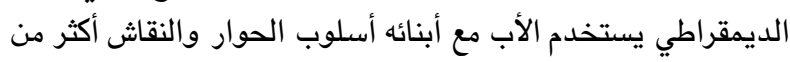
أسلوب القمع والعقاب (Shaw, 2008) .

كما أشارت النتائج إلى عدم وجود قدرة تنبؤية لجميع المتغيرات المتنبئة السابقة في استراتيجية الدعم الاجتماعي التي

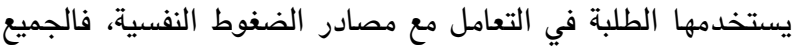

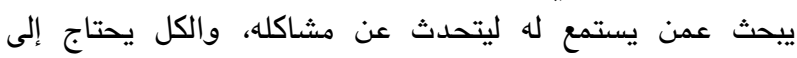
النصيحة والاستفادة من خبرات الآخرين وتجاربهه، بغض النظر عن لهن

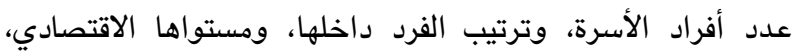

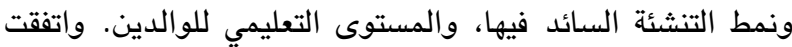

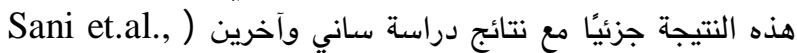

الاندفاعية التي يتميز بها الثباب. واتفقت هذه النتيجة مع نتائج

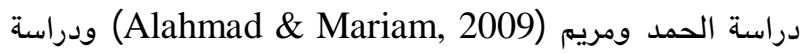
العويدة (Aloaidah, 2009) اللتين أشارتا إلى أن استراتيجية

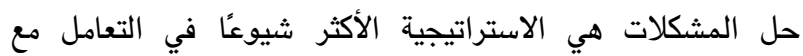
الضغوط النفسية لدى الطلبة. فيما اختلفت مع نتائج دراسة بديرائه Chun \& Poole, ) ودراسة شن وبول (Budair, 2013) 2009) اللتين أشارتا إلى حصول استراتيجية حل المشكلات في ودرل

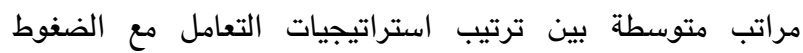

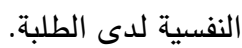

ويُلاحظ من النتائج السابقة أن استراتيجية إعادة البناء

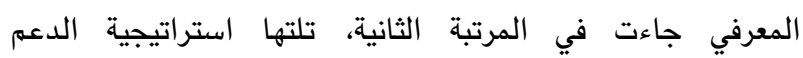
الاجتماعي في المرتبة الثالثة، وجاء ذلك مباشرة بعد المتية استراتيجية

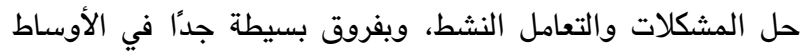

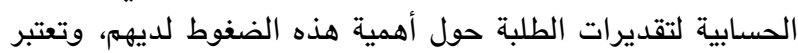

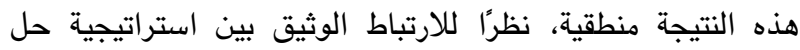
المشكلات وإعادة البناء المعرفي من جهة، وبين حل هل المشكلات والدعم الاجتماعي من جهة أخرى، ومما يؤكد ذلك ما أشار إليه

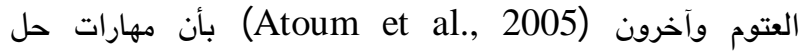
المشكلات تتمثل في: البنية المعرفية؛ واستراتيجيات حل المشكلة،

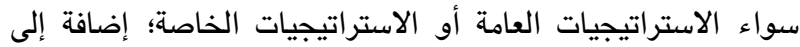

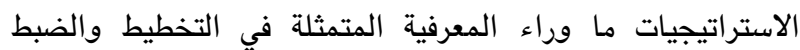

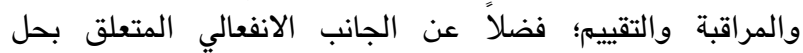

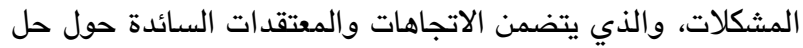

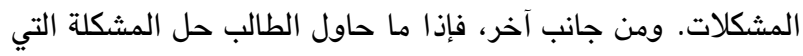

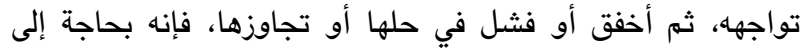

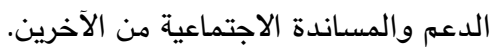

ومن جانب ثالث، يعد استخدام استراتيجية إعادة البناء المعرفي مؤشرًا على درجة مناسبة من النضج والوعي لدى الطلبة

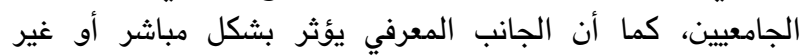

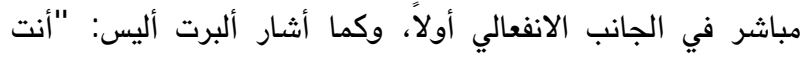

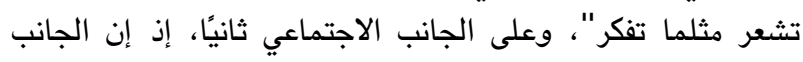

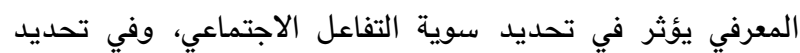

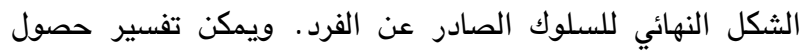

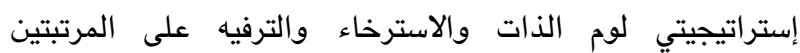

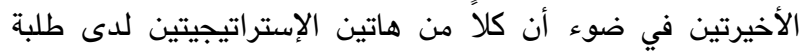

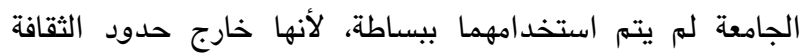

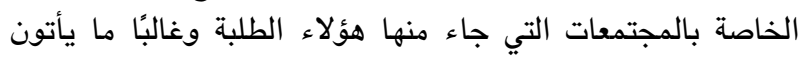
من القرى المجاورة، وغالبا ما يلجأ هؤلاء الطلبة إلى أساليب أكثر الطراء

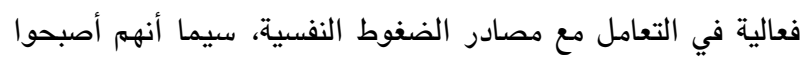
على درجة من الوعي الشخصي والنضج الفكري وتحمل المسؤولية. واتفقت هذه النتيجة مع نتائج بعض الدراسات السابقة

Pierceall \& :Almohtaseb, 2008 ؛Alsmadi, 2015) (Keim, 2007 
إلى وجود ارتباط بين استراتيجيات التفاعل والمستوى التعليمي

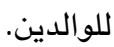

وأشارت النتائج إلى أنه كلما زاد ترتيب الطالب باتجاه الأخير

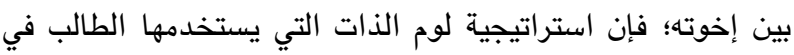

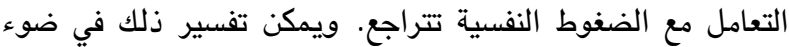

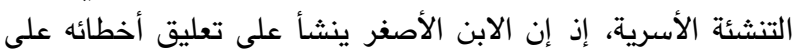

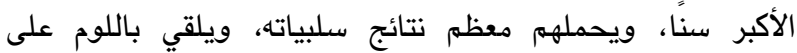

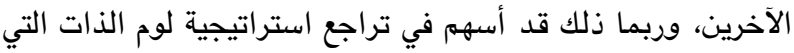

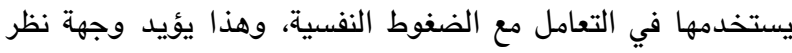

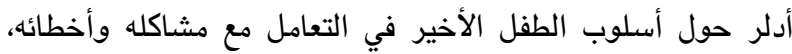
حيث طور أسلوبًا اتكاليًا (Corey, 2011).

وتبين من النتائج كذلك أنه كلما زاد الدخل الشهري للأسرة

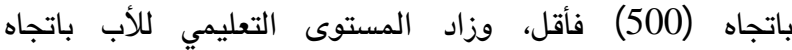

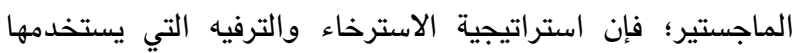

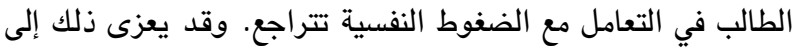

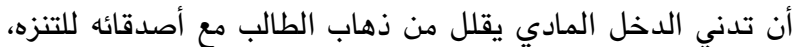

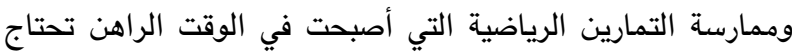

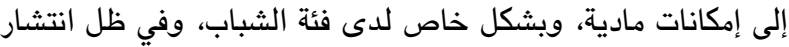

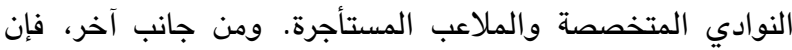

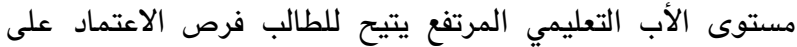

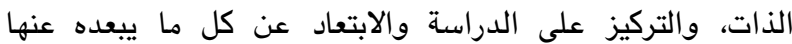

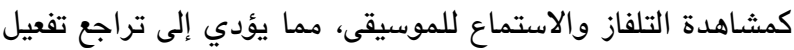

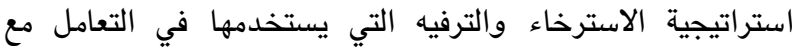

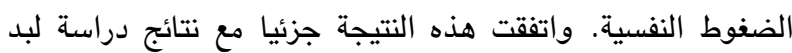

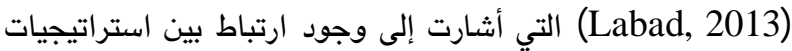
التفاعل والمستوى التعليمي للوالدين.

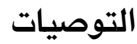

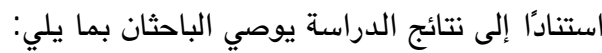

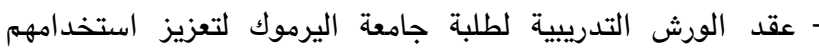

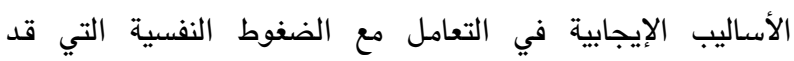

تواجههم.

- عقد ورث تدريبية لتوعية الأمهات من حملة الدبلوم فأقل في إثراء أساليب إعادة البناء المعرفي للأبناء، وحل المشكلات لتات كأساليب للتعامل مع الأزمات التي قد تواجهـهم.

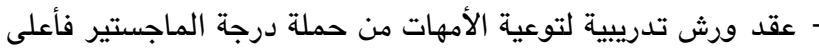

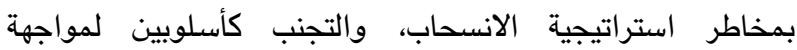
الضغوط النفسية التي قد تواجه أبناءهن من طلبة الجامعات.

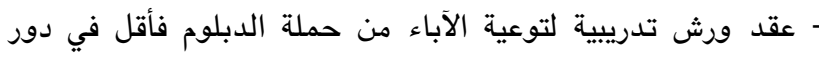
التدين، والتفريغ الانفعالي في التخفيف من الضغوط التاء من النفسية التي قد تواجه أبناءهم من طلبة الجامعات.

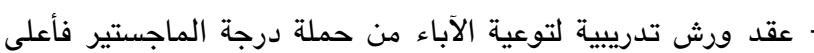

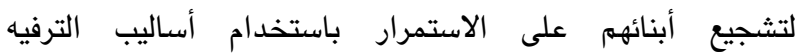

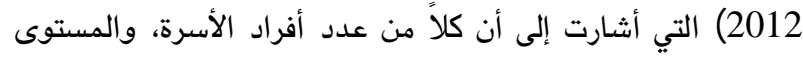

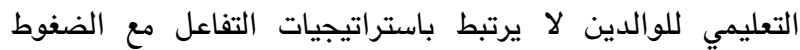

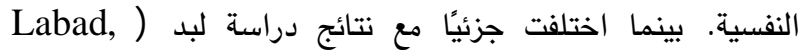

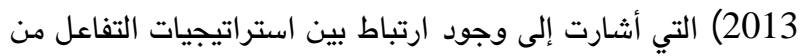

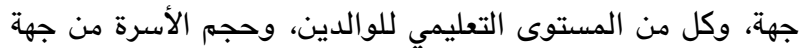

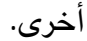

وأشارت النتائج كذلك إلى أنه كلما زاد المستوى التعليمي

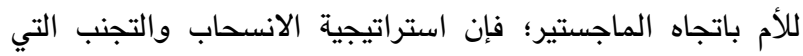

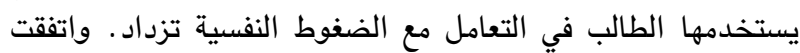
هذه النتيجة جزئًا مع نتائج دراسة لبد التيامل (Labad, 2013) التي

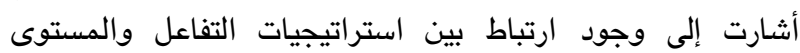

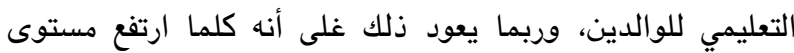

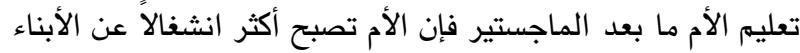

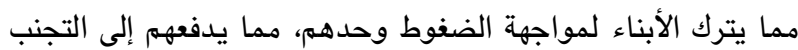

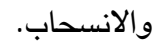

كما أكدت النتائج أنه كلما كان المستوى التعليمي للأم من

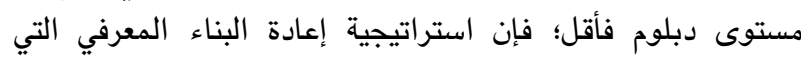

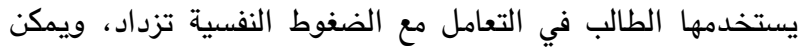

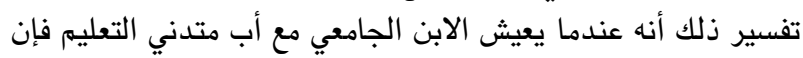

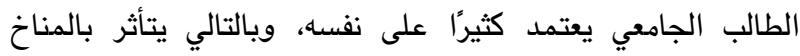

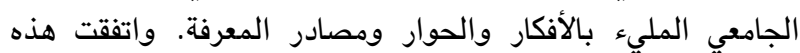
النتيجة جزئيًا مع نتائج دراسة لبد الجئ (Labad, 2013) التي أشارت

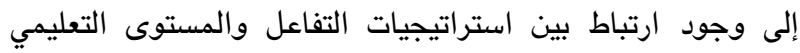

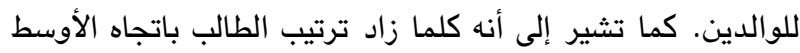
بين أخوته؛ فإن استراتيجية إعادة البناء المعرفي التي يستخدمها

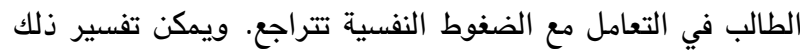

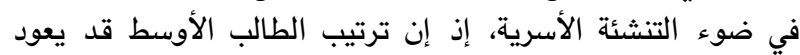
عليه بالاعتماد على الآخرين في مواجهة المشكلات، وخاصة إلى إخوانه

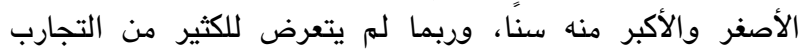

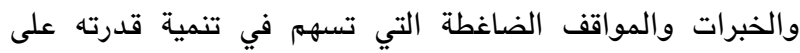

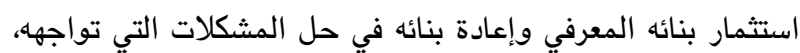

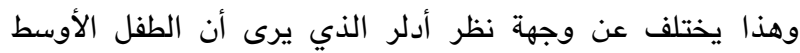

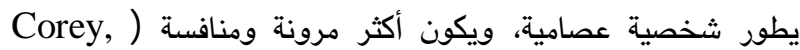

. (2011

كما أوضحت النتائج أنه كلما زاد المستوى التعليمي للأب التاب التفان

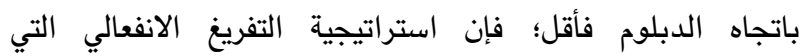

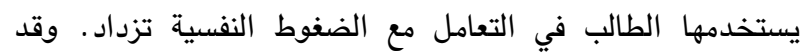

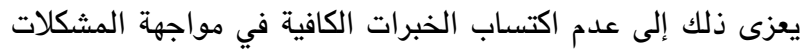

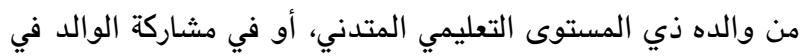

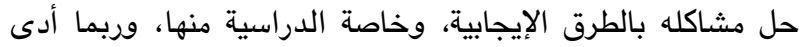

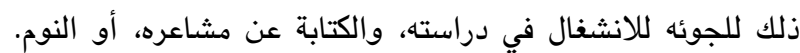

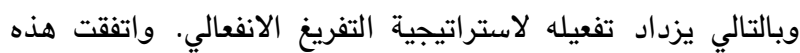
النتيجة جزئيًا مع نتائج دراسة لبد (Labad, 2013) التي أشارت 
Alrashdan, A. (2005). Education \& socialization. Amman: Wael Press.

Alshakah, A. (2009). Facing strategies of daily life stressors among Alquds Open University students in Nablus Governorate. Alnajah University Journal for Research, 32(2), 351378.

Alshamary, M. (2015). Social phobia and psychological stress resources among preparatory college students of Hail University. Unpublished Master Thesis, Yarmouk University, Irbid, Jordan.

Alsmadi, E. (2015). Psychological stress resources among world Islamic University students and coping strategies. College of Education Journal.1(5), 135-185.

Alyamani, A. \& Alzuabi, N. (2013). Psychological stress coping strategies among educational bachelor's degree students in the Jordanian Universities. Alquds Open University Journal for Educational and Psychological studies and Researches, 1(2), 226-240.

Alzuod, N. (2006). Stress coping strategies among Qatar university students and its relation to some variables. Educational Office of Gulf Countries. (99), 1-12.

Aoudeh, A. (2010). Measurement and evaluation in teaching process. Irbid: Alamal library.

Atoum, A., Allawneh, S., Aljarrah, A., \& Abu gazal, M. (2005). Educational psychology: Theory and application. Amman: Dar Almasearah.

Budair, E. (2013). Family support and its relation to coping strategies of life stressors among college students. Sciences, Arts, Studies, \& Egyptian Research. 25(1), 227-254.

Chun, J. \& Poole, D. (2009). Conceptualizing stress and coping strategies of Korean social work students in the United States: A concept mapping application. Journal of Teaching in Social Work, 29(1), 1-17.

Corey, G. (2011). Theory and practice in counseling and psychotherapy. (Sameh Alkhofash, Trans.). Amman; Dar Alfekir.

Dukhan, N. \& Alalhajar, B. (2006). Psychological stress among Islamic University students and its relation to their psychological hardness. Islamic University Journal (Humanitiesseries), 14(1),369-389.

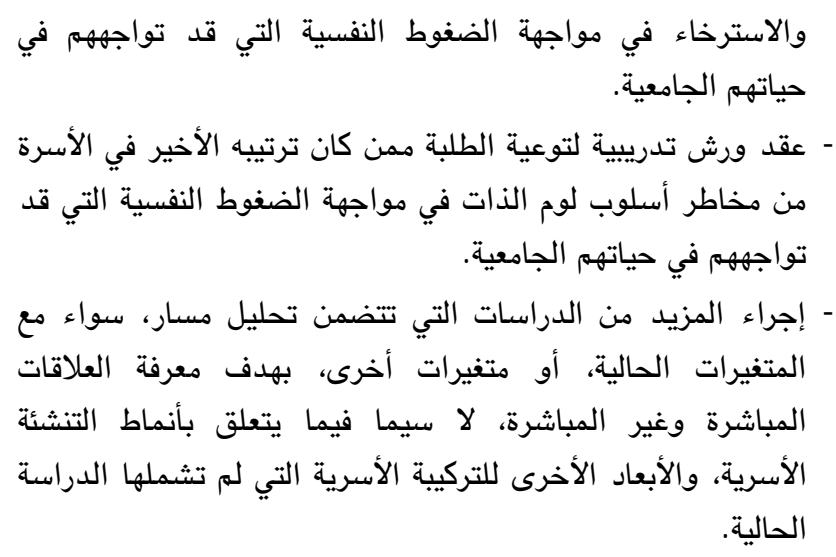

\section{References}

Ajbory, K. (1991). Effect of cognitive dissonance in changing attitudes toward others in light of parenting style. Unpublished Master Thesis, Almustanseriah University, Bagdad, Iraq.

Alahmad, A. \& Mariam, R. (2009). Coping strategies with stress among college students: Field study for a sample of Damascus University. Educational \& Psychological Journal, 10(1), 24-34.

Alasam, A. (2010). Family atmosphere and its relation to achievement motivation among non Jordanian students in Yarmouk University. Arabic Childhood Journal, 1(57), 9-41.

Alkhazrajy, D. (2007). Emotional intelligence and its relation with parenting style among preparatory students. Unpublished Master Thesis, Dialy University, Bagoubah, Iraq.

Almeshaan, O. (2004). Psychological stressors: Practical model and skills for success. Kuwait: Dar Elorobah Press.

Almohtaseb, M. (2008). Optimism and pessimism and its relation to stressing daily life events and coping strategies among Alquds University students. Unpublished Master Thesis. Alquds University, Palestine.

Almomani, F \& Alzghool, R. (2011). Coping strategies among survivors of Amman hotels explosion and their families. Humanities and Social Sciences Journal. 38(2), 391-411.

Almoselly, W. \& Mahmoud, H. (2007). Mental health. Amman: Zahran Press.

Alquraan, M. (2017). The predictability of family structure for stressors and coping strategies among Yarmouk University students. Unpublished Master Thesis, Yarmouk University, Irbid, Jordan. 
Guasmehm A. \& Gharaibeh, F. (2005). Learning motivation and its relation to some variables. Educational Sciences Journal. 1(7), 177-193.

Kumar, S. \& Buhkar, P. (2013). Stress level and coping strategies of college students, Journal of Physical Education and Sports Management, 4(1), 5-11.

Labad, Moataz (2013). Life stressors coping styles and its relation to psychological adjustment among community college students in Gaza strip. Unpublished Master Thesis. Alazhar University, Gaza, Palestine.

Mahafzah, S. \& Alzuabi, Z. (2008). Effect socioeconomic and academic factors in forming self-concept among Hashemite University. Educational Sciences, 35(1), 110127.

Mazahreh, A. (2009). Family and child rising. Amman; Dar El Manaheg.

O’Brien, L., Mathieson, K., Leafman, J. \& Spearman, L. (2012). Level of stress and common coping strategies among physician assistant students. The Journal of Physician Assistant Education, 23(4), 9-25.

Pierceall, E. \& Keim, M. (2007). Stress and coping strategies among community college students. Community college Journal of Research and Practice, 31(9), 703-712.
Ramadan, J. (1999). Psychological burnout and adjustment strategies among workers in ministries of Palestinians national authority. Unpublished Master Thesis. Alnajah University, Nablus, Palestine.

Sabbar, H. (2011). Psychological stress and its relation to self-confidence among college students. Alfarahidi Arts Journal, 9, 279-289.

Sani, M., Mahfouz, M., Bani, I., Alsomily, A., Alagi, D., Madkhaly, F., Hakami, A., Shaqraa, S. Al Ebrahim, S., Mashiakhi, S., Ageel, B. \& Asiri, S. (2012). Prevalence of stress among medical students in Jizan University, Kingdom of Saudi Arabia. Gulf Medical Journal, 1(1), 19-25.

Shaw, N. (2008). The relationship between perceived parenting style, academic selfefficacy and college adjustment of freshman engineering students. Unpublished Ph.D. Dissertation, University of North Texas, Denton, Texas.

Smadi, A. \& Abdallah, A. (1996). Psychological problems produced by Arab Family system: Analytic study. Psychological Counseling Journal, 5, 89-114.

Yu, J. \& Gambel, C. (2008). Familial correlates of overt and relational aggression between young adolescent siblings. Journal of Youth Adolescence, 3(7), 231-254. 